Application of the Radial Integration Method for the Buckling Analysis of Plates with Shear Deformation

R.A. Soares Jr. ${ }^{1}$, L. Palermo Jr. ${ }^{1}$, L.C. Wrobel ${ }^{2}$

${ }^{1}$ School of Civil Engineering, Architecture and Urban Design, State University of Campinas, Caixa Postal 6143, CEP 13083-889, Campinas, Brazil

${ }^{2}$ Brunel University London, Department of Mechanical Engineering, Uxbridge UB8 3PH, UK; also, at Department of Civil and Environmental Engineering, PUC-Rio - Pontifical Catholic University of Rio de Janeiro, Rio de Janeiro, Brazil

\begin{abstract}
This work presents a novel formulation of the Boundary Element Method (BEM) with the Radial Integration Method (RIM) to calculate the critical loads of the plate buckling problem with shear deformation. An alternative formulation is adopted where the effect of the geometric non-linearity is described by using the first derivative of the function for the out-of-plane displacements. The RIM is developed for this problem and used to convert the resulting domain integrals into equivalent boundary integrals. The results are compared with other results available in the literature and with the results obtained with the Dual Reciprocity Method (DRM). The advantages of using the RIM are discussed at the end of this work.
\end{abstract}

Keywords: radial integration method, plate buckling, shear deformation, Reissner plates, boundary elements.

\title{
Introduction
}

The present work develops an alternative formulation of the Radial Integration Method (RIM) within a Boundary Element Method (BEM) formulation for calculating the critical load in plate buckling problems. The bending model takes into account the effect of shear deformation as the classical plate bending theory [1] presents difficulties in the modelling of the plate borders and/or in the representation of the stresses around holes with diameter lower than or equal to the plate thickness. The formulation employed in this work assumes that the effect of shear deformation is constant along the plate thickness, as considered by Reissner [2] and Mindlin [3]. The relations between the Reissner model and the classical bending theory are discussed by Timoshenko and Woinowsky-Krieger [4].

The effect of shear deformation has an influence on the value of critical loads in plates, besides the flexural rigidity, as can be explicitly demonstrated in the analytical solution of the plate buckling problem [5], or through the use of numerical analysis. The numerical treatment of the 
problem can be found in the literature by using different numerical methods, such as the Finite Element Method (FEM) [6, 7], meshless methods [8,9], the finite strip method $[10,11]$, as well as the method of conjugate load/displacements [12].

The Boundary Element Method (BEM) [13] removed the need for domain integrations through the representation of linear problems using boundary integral equations. When the problem introduces domain integrals due to the effect of non-linearities, domain integration becomes necessary. This is the case in the plate buckling problem due to the effect of geometric non-linearity $(G N L)$. Various methods associated with the BEM have been developed to remove the need for domain integration, such as the Dual Reciprocity Method (DRM) introduced by Nardini and Brebbia [14], as explained in detail in [15], the Multiple Reciprocity Method (MRM), developed by Nowak and Brebbia [16], the Analog Equation Method developed by Yiotis and Katsikadelis [17], the Radial Integration Method (RIM) developed by Gao [18], and others such as the direct conversion method presented by Wen, Aliabadi and Rooke [19].

Purbolaksono and Aliabadi [20] employed the DRM for the plate buckling problem with shear deformation, by using a formulation where the effect of the GNL is described by using the second derivative of the out-of-plane displacements, or the second derivative of the deflections [4]. An alternative BEM formulation for plate buckling using only the first derivative of the deflections was developed by Soares and Palermo [21], which results in two integrals related to the GNL, one computed along the boundary and the other over the domain. A DRM formulation for this problem was developed in [22] to remove the domain integral in the formulation developed in [21].

The need for the development of particular solutions in the DRM is a restriction for its general application, as there may be some difficulties in obtaining the particular solutions for more complex problems involving anisotropy [23]. As an alternative to the DRM, this work develops a formulation of the RIM for the plate buckling problem with shear deformation. One of the bases for the formulation of the RIM is that polar coordinates are used in the domain integration [24].

Based on his previous work [25], Gao [18] generalized the application of polar coordinates, in conjunction with radial basis functions (RBFs), to convert domain integrals into approximate boundary integrals, calling the new method the RIM. Gao also showed some advantages of the RIM with respect to other methods, such as the free choice of RBFs without the need to calculate particular solutions, and its ease of implementation in existing codes. These advantages attracted the attention of other researchers, and the RIM has now been applied to many engineering problems such as heat transfer problems [26, 27], convection problems [28], diffusion problems [29, 
30], elasticity and elastoplasticity problems [31-33], acoustic problems [34], vibration problems [35], classical plate bending problems [36], plate problems based on Mindlin's model [37], buckling of laminate composites [38] and thin shell buckling problems [39].

The present work develops and applies the RIM for transforming the domain integral for the plate buckling problem with shear deformation presented in [21]. The formulation is validated with tests on square, triangular and skew plates with or without central holes, for plates with different boundary conditions, different ratios between plate thickness and plate length and different types of loading. The numerical results are compared with those obtained by cell integration and by the DRM, and with other results from the literature.

\section{Boundary Integral Equations}

The boundary integral equation for displacements (DBIE), rotations and deflections for the plate buckling problem used in [21] is given as follows:

$$
\begin{aligned}
\frac{1}{2} C_{i j}\left(x^{\prime}\right) u_{j}\left(x^{\prime}\right) & +\int_{\Gamma}\left[T_{i j}\left(x^{\prime}, x\right) u_{j}(x)-U_{i j}\left(x^{\prime}, x\right) t_{j}(x)\right] d \Gamma(x) \\
& =\iint_{\Omega} U_{i 3}\left(x^{\prime}, X\right)\left[\frac{\partial}{\partial X_{\alpha}}\left(N_{\alpha \beta} \frac{\partial u_{3}}{\partial X_{\beta}}\right)\right] d \Omega(X)
\end{aligned}
$$

where $C_{i j}$ is an element of matrix $C$ related to the boundary geometry at the source point, which becomes the identity matrix when a smooth boundary is considered, $u_{\alpha}$ is the plate rotation in direction $\alpha$, and $u_{3}$ is the plate deflection. $U_{i j}$ represents the rotation $(j=1,2)$ or the deflection $(j=3)$ due to a unit couple $(i=1,2)$ or a unit point force $(i=3), T_{i j}$ represents the moment $(j=1,2)$ or the shear force $(\mathrm{j}=3)$ due to a unit couple $(\mathrm{i}=1,2)$ or a unit point force $(\mathrm{i}=3)$. The functions $U_{i j}$ and $T_{i j}$ are related to the fundamental solution of the problem. $X$ is the coordinate of a field point in the plate domain, $x^{\prime}$ and $x$ are coordinates of the source and the field points on the plate boundary, $N_{\alpha \beta}$ are the in-plane forces from the generalized plane stress problem related to the plate buckling.

The divergence theorem was used in [21] to allow the domain integral to employ only the first derivatives of the transverse displacement, as shown in equation (2):

$$
\begin{aligned}
\iint_{\Omega} U_{i 3}\left(x^{\prime}, X\right)[ & \left.\frac{\partial}{\partial X_{\alpha}}\left(N_{\alpha \beta} \frac{\partial u_{3}(X)}{\partial X_{\beta}}\right)\right] d \Omega(X) \\
& =\int_{\Gamma} n_{\alpha}(x) N_{\alpha \beta}(x) u_{3, \beta}(x) U_{i 3}\left(x^{\prime}, x\right) d \Gamma(x)-\iint_{\Omega} N_{\alpha \beta}(X) u_{3, \beta}(X) U_{i 3, \alpha}\left(x^{\prime}, X\right) d \Omega(X)
\end{aligned}
$$


Substituting the result of equation $\{2\}$ in equation (1), the displacement integral equation with the effect of geometrical non-linearity (GNL) is obtained. As can be observed, only the first derivative of the transverse displacements appears in two integrals in the equation, one in the domain and the other on the boundary, as given by equation (3):

$$
\begin{aligned}
\frac{1}{2} C_{i j}\left(x^{\prime}\right) u_{j}\left(x^{\prime}\right) & +\int_{\Gamma}\left[T_{i j}\left(x^{\prime}, x\right) u_{j}(x)-U_{i j}\left(x^{\prime}, x\right) t_{j}(x)\right] d \Gamma(x) \\
& =\int_{\Gamma} n_{\alpha}(x) N_{\alpha \beta}(x) u_{3, \beta}(x) U_{i 3}\left(x^{\prime}, x\right) d \Gamma(x)-\iint_{\Omega} N_{\alpha \beta}(X) u_{3, \beta}(X) U_{i 3, \alpha}\left(x^{\prime}, X\right) d \Omega(X)
\end{aligned}
$$

where $\mathrm{x}^{\prime}$ and $\mathrm{x}$ are the field and source points, respectively, both along the boundary, while $\mathrm{X}^{\prime}$ and $\mathrm{X}$ are the field and source points, respectively, in the domain.

The second integral equation is used to obtain the derivative of the deflections, which are needed in the eigenvalue problem related to the critical load, and is given by equation (4):

$$
\begin{aligned}
g u_{3, \gamma}\left(x^{\prime}\right)=\int_{\Gamma}\{ & n_{\alpha}(x) M_{3 \alpha \beta, \gamma}\left(x^{\prime}, x\right) u_{\beta}(x)+n_{\beta}(x) Q_{3 \beta, \gamma}\left(x^{\prime}, x\right) u_{3}(x)-U_{3 \beta, \gamma}\left(x^{\prime}, x\right) t_{\beta}(x) \\
& \left.-U_{33, \gamma}\left(x^{\prime}, x\right) t_{3}(x)\right\} d \Gamma(x)-\int_{\Gamma} n_{\alpha}(x) N_{\alpha \beta}(x) u_{3, \beta}(x) U_{i 3, \gamma}\left(x^{\prime}, x\right) d \Gamma(x) \\
& +\iint_{\Omega} N_{\alpha \beta}(X) u_{3, \beta}(X) \frac{\partial}{\partial X_{\gamma}}\left[U_{33, \alpha}\left(x^{\prime}, X\right)\right] d \Omega(X)
\end{aligned}
$$

where " $g$ " takes the value 0.5 for a source point along a smooth boundary, and the value of 1 for a source point in the domain.

\section{The Radial Integration Method}

The RIM was employed in this work to treat the domain integrals in equations ( 3 ) and (4). The method is based on two premises: the conversion to polar coordinates and the use of radial basis functions to approximate the domain loads. Equation (5) shows the integration of one of the domain integrals using polar coordinates [32]:

$$
\iint_{\Omega} F(X) d \Omega=\int_{\Gamma} \frac{1}{r} \frac{d r}{d n}\left(\int_{0}^{r} F(r) r d r\right) d \Gamma
$$

where $F(X)$ is the function to be integrated over the domain. For simple functions (constant, polynomial), the integral in the polar coordinate $r$ may be obtained analytically. 
The RIM will initially be applied to the domain integral that appears in equation (3). This integral contains the first derivative of the displacement fundamental solution, as shown in equation (6):

$$
I_{1}=\iint_{\Omega} N_{\theta \beta}(X) u_{3, \beta}(X) U_{i 3, \theta}\left(x^{\prime}, X\right) d \Omega(X)=\iint_{\Omega} b_{\theta}(X) U_{i 3, \theta}\left(x^{\prime}, X\right) d \Omega(X)
$$

with,

$$
b_{\theta}(X)=N_{\theta \beta}(X) u_{3, \beta}(X)
$$

The function $b_{\theta}(X)$, given by the product of the tensor of the initial tensions in the plane of the plate $N_{\theta \beta}(X)$ by the gradient of the deflections $U_{i 3, \theta}\left(x^{\prime}, X\right)$, is approximated by a radial basis function (RBF) centered in a number of points along the boundary (N) and the domain (L) of the problem:

$$
\begin{aligned}
& b_{\theta}(X) \simeq \sum_{m=1}^{N+L} \alpha_{\theta}^{m} f^{m} \\
& {\left[\alpha_{\theta}^{m}\right]=[F]^{-1}\left[b_{\theta}\right]}
\end{aligned}
$$

The approximation coefficients $\alpha_{\theta}^{m}$ are obtained through the solution of a linear system of equations generated from equation (7) and written in the matrix form (8). Matrix [F] is generated with the values of the radial basis functions $f(R)$, and its inverse is multiplied by a vector obtained through the product of the tensor of initial tensions in the plane of the plate by the gradient of the deflections $\left[N_{\theta \beta} u_{3, \beta}\right]$ to obtain the vector of the approximation coefficients $\alpha_{\theta}^{m}$.

Substituting the relation given by equation (7) into equation (6), and using equation (5), it is possible to convert the domain integral into a sum of boundary integrals by using the RIM:

$$
I_{1}=\sum_{m=1}^{N+L} \alpha_{\theta}^{m}\left\{\int_{\Gamma} \frac{1}{r} \frac{d r}{d n}\left(\int_{0}^{r(Q)} U_{i 3, \theta}(r) f(R) r d r\right) d \Gamma\right\}
$$

The variable $R$ of the radial basis function $f(R)$ in equation (9) may be written in terms of the variables $\bar{R}$ and $r$ shown in Figure 1, where the positions of the source point $p$, the field point $Q$ and the pole $A$ of the radial basis functions $f(R)$ are shown. 


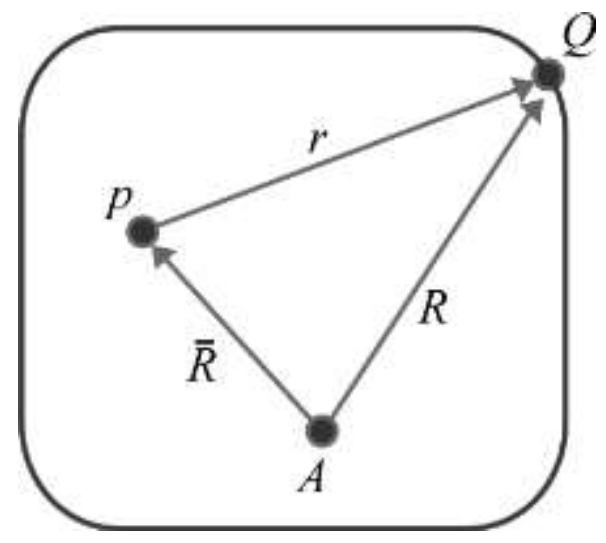

Figure 1 - Relation between the radius $(r)$ used in the fundamental solution and the radius $(R)$ of the radial basis function, as shown in [32]

The following relations can be extracted from Figure $1[18]$ :

$$
R=\sqrt{r^{2}+s r+\bar{R}^{2}} ; \quad \bar{R}=\sqrt{\left(x_{p}-x_{A}\right)^{2}+\left(y_{p}-y_{A}\right)^{2}} ; \quad s=2\left[r_{, 1}\left(x_{p}-x_{A}\right)+r_{, 2}\left(y_{p}-y_{A}\right)\right]
$$

Substituting the domain integral in equation (3) by its equivalent boundary integral converted by the RIM in equation (9), we obtain the following displacement boundary integral equation given by equation (10):

$$
\begin{aligned}
\frac{1}{2} C_{i j}\left(x^{\prime}\right) u_{j}\left(x^{\prime}\right) & +\int_{\Gamma}\left[T_{i j}\left(x^{\prime}, x\right) u_{j}(x)-U_{i j}\left(x^{\prime}, x\right) t_{j}(x)\right] d \Gamma(x) \\
& =\int_{\Gamma} n_{\theta}(x) N_{\theta \beta}(x) u_{3, \beta}(x) U_{i 3}\left(x^{\prime}, x\right) d \Gamma(x) \\
& -\sum_{m=1}^{N+L} \alpha_{\theta}^{m}\left\{\int_{\Gamma} \frac{1}{r} \frac{d r}{d n}\left(\int_{0}^{r(Q)} U_{i 3, \theta}(r) f(R) r d r\right) d \Gamma\right\}
\end{aligned}
$$

The application of the RIM to approximate the domain integral in equation (4) with a sum of boundary integrals is similar to that of equation (3). Thus, the integral equation for the gradient of the deflections is given by equation (11):

$$
\begin{aligned}
g u_{3, \gamma}\left(x^{\prime}\right)=\int_{\Gamma}\left\{n_{\alpha}(x) M_{3 \alpha \beta, \gamma}\left(x^{\prime}, x\right) u_{\beta}(x)+n_{\beta}(x) Q_{3 \beta, \gamma}\left(x^{\prime}, x\right) u_{3}(x)-U_{3 \beta, \gamma}\left(x^{\prime}, x\right) t_{\beta}(x)\right. \\
\left.-U_{33, \gamma}\left(x^{\prime}, x\right) t_{3}(x)\right\} d \Gamma(x)-\int_{\Gamma} n_{\alpha}(x) N_{\alpha \beta}(x) u_{3, \beta}(x) U_{i 3, \gamma}\left(x^{\prime}, x\right) d \Gamma(x) \\
+\sum_{m=1}^{N+L} \alpha_{\theta}^{m}\left\{\int_{\Gamma} \frac{1}{r} \frac{d r}{d n}\left(\int_{0}^{r(Q)} U_{33, \theta \gamma}(r) f(R) r d r\right) d \Gamma\right\}
\end{aligned}
$$


The existence of a singularity in the fundamental solution $\mathrm{U}_{\mathrm{i} 3, \theta}$ and its differentiation in equation (4), as we are dealing with the integral equation for the gradient of the deflections, need special care in the application of the RIM. Consider the domain integral in equation (4):

$$
I_{2}=\iint_{\Omega} N_{\theta \beta}(X) u_{3, \beta}(X) U_{33, \theta \gamma}\left(X^{\prime}, X\right) d \Omega(X)=\iint_{\Omega} b_{\theta}(X) \frac{\partial}{\partial x_{\gamma}}\left[U_{33, \theta}\left(X^{\prime}, X\right)\right] d \Omega(X)
$$

where,

$$
U_{33, \theta \gamma}=\frac{1}{4 \pi D}\left(\delta_{\theta \gamma}\left(\ln (z)-\frac{1}{2}\right)+r_{, \theta} r_{, \gamma}\right)-\frac{1}{\pi D(1-v) \lambda^{2} r^{2}}\left(\delta_{\theta \gamma}-2 r_{, \theta} r_{, \gamma}\right)
$$

An integral of the Cauchy type appears in the domain integral involving the fundamental solution $U_{33, \theta \gamma}$. According to the works of Bui [40] and Telles [41], when evaluating a domain integral of the Cauchy type, it is necessary to start with a limit analysis to verify the existence of free terms. Considering a source point in the domain, an infinitesimal circular region $\Omega_{\varepsilon}$ of radius $\varepsilon$ centered at the source point is initially extracted from the domain. The domain load inside this infinitesimal region is assumed to be constant. The domain integral in equation (12) is then written as follows:

$$
\begin{aligned}
I_{2}=\iint_{\Omega} b_{\theta}(X) & \frac{\partial}{\partial x_{\gamma}}\left[U_{33, \theta}\left(X^{\prime}, X\right)\right] d \Omega(X) \\
= & \iint_{\Omega-\Omega_{\varepsilon}} b_{\theta}(X) \frac{\partial}{\partial x_{\gamma}}\left[U_{33, \theta}\left(X^{\prime}, X\right)\right] d \Omega(X) \\
& +b_{\theta}\left(X^{\prime}\right) \iint_{\Omega_{\varepsilon}} \frac{\partial}{\partial x_{\gamma}}\left[U_{33, \theta}\left(X^{\prime}, X\right)\right] d \Omega_{\varepsilon}(X)
\end{aligned}
$$

Applying the divergence theorem to the second integral on the right side of equation (13), the following equation is obtained:

$$
I_{2}=\iint_{\Omega-\Omega_{\varepsilon}} b_{\theta}(X) \frac{\partial}{\partial x_{\gamma}}\left(U_{33, \theta}\left(X^{\prime}, X\right)\right) d \Omega(X)+b_{\theta}\left(X^{\prime}\right) \int_{\Gamma_{\varepsilon}}\left(U_{33, \theta}\left(X^{\prime}, X\right)\right) n_{\gamma} d \Gamma_{\varepsilon}(x)
$$

where $\Gamma_{\varepsilon}$ is the boundary of a circle of radius $\varepsilon$.

Converting the second integral on the right side of equation (14) to polar coordinates, and carrying out a limit analysis when the radius $\varepsilon$ tends to zero gives:

$$
I_{2}=\iint_{\Omega} b_{\theta}(X) \frac{\partial}{\partial x_{\gamma}}\left(U_{33, \theta}\left(X^{\prime}, X\right)\right) d \Omega(X)-\frac{b_{\theta}\left(X^{\prime}\right) \delta_{\theta \gamma}}{D(1-v) \lambda^{2}}
$$


where a free term is obtained on the right side of equation (15) when the source point is in the domain. When the source point is located in a smooth part of the boundary, the integration is carried out around half a circle and the free term in equation (15) is divided by 2 . The first integral in equation (15) should be evaluated in the sense of Cauchy Principal Value. The integral equation for the gradient of the deflections using the RIM and with the free term is given by:

$$
\begin{aligned}
g u_{3, \gamma}\left(x^{\prime}\right)=\int_{\Gamma}\left\{n_{\alpha}(x) M_{3 \alpha \beta, \gamma}\left(x^{\prime}, x\right) u_{\beta}(x)+n_{\beta}(x) Q_{3 \beta, \gamma}\left(x^{\prime}, x\right) u_{3}(x)-U_{3 \beta, \gamma}\left(x^{\prime}, x\right) t_{\beta}(x)\right. \\
\left.-U_{33, \gamma}\left(x^{\prime}, x\right) t_{3}(x)\right\} d \Gamma(x)-\int_{\Gamma} n_{\alpha}(x) N_{\alpha \beta}(x) u_{3, \beta}(x) U_{i 3, \gamma}\left(x^{\prime}, x\right) d \Gamma(x) \\
\quad+\sum_{m=1}^{N+L} \alpha_{\theta}^{m}\left\{\int_{\Gamma} \frac{1}{r} \frac{d r}{d n}\left(\int_{0}^{r(Q)} U_{33, \theta \gamma}(r) f(R) r d r\right) d \Gamma-g \frac{f(\bar{R}) \delta_{\theta \gamma}}{D(1-v) \lambda^{2}}\right\}
\end{aligned}
$$

The treatment of the radial integral with the term $U_{33, \theta \gamma}(r) f(R) r$ with a singularity of the Cauchy type is based on the work of Guiggiani and Gigante [42]. The singularity subtraction technique can be used in this treatment and, to this end, a function related to the integrand is defined with respect to the radius, as follows:

$$
h_{\theta \gamma}(r)=\left(f(R) U_{33, \theta \gamma} r\right) r=f(R) U_{33, \theta \gamma} r^{2}
$$

The function defined in equation (17) will be used in the singularity subtraction technique for the treatment of the radial integral:

$$
\begin{aligned}
\int_{\Gamma} \frac{1}{r} \frac{d r}{d n}\left(\int_{0}^{r(Q)} U_{33, \gamma \theta}(r) f(R) r d r\right) d \Gamma & \\
& =\int_{\Gamma} \frac{1}{r} \frac{d r}{d n}\left(\int_{0}^{r(Q)} \frac{h_{\theta \gamma}(r)-h_{\theta \gamma}(\bar{R})}{r} d r\right) d \Gamma \\
& +\int_{\Gamma} \frac{1}{r} \frac{d r}{d n} h_{\theta \gamma}(\bar{R})\left(\int_{0}^{r(Q)} \frac{1}{r} d r\right) d \Gamma
\end{aligned}
$$

where,

$$
h_{\theta \gamma}(\bar{R})=\lim _{r \rightarrow 0} h_{\theta \gamma}(r)=f(\bar{R})\left(-\frac{1}{\pi D(1-v) \lambda^{2}}\left(\delta_{\theta \gamma}-2 r_{, \theta} r_{, \gamma}\right)\right)
$$

The first integral on the right side of equation (18) can be calculated by using Gauss quadrature. In the second integral on the right side of equation (18), it is necessary to remove a circle 
of radius $\varepsilon$ in the lower limit of the radial integral. It can be shown that the integral along the circle of radius $\varepsilon$ applied to the lower limit is equal to zero, and equation (18) can then be written as follows:

$$
\begin{aligned}
\int_{\Gamma} \frac{1}{r} \frac{d r}{d n}\left(\int_{0}^{r(Q)} U_{33, \gamma \theta}(r) f(R) r d r\right) d \Gamma \\
\quad=\int_{\Gamma} \frac{1}{r} \frac{d r}{d n}\left(\int_{0}^{r(Q)} \frac{h_{\theta \gamma}(r)-h_{\theta \gamma}(\bar{R})}{r} d r\right) d \Gamma+\int_{\Gamma} \frac{1}{r} \frac{d r}{d n} h_{\theta \gamma}(\bar{R}) \ln (r(Q)) d \Gamma
\end{aligned}
$$

The integral equation for the gradient of the deflections, including the free term and the treatment of the radial integral of the Cauchy type, is given by:

$$
\begin{aligned}
u_{3, \gamma}\left(x^{\prime}\right)=\int_{\Gamma}\{ & n_{\alpha}(x) M_{3 \alpha \beta, \gamma}\left(x^{\prime}, x\right) u_{\beta}(x)+n_{\beta}(x) Q_{3 \beta, \gamma}\left(x^{\prime}, x\right) u_{3}(x)-U_{3 \beta, \gamma}\left(x^{\prime}, x\right) t_{\beta}(x) \\
& \left.-U_{33, \gamma}\left(x^{\prime}, x\right) t_{3}(x)\right\} d \Gamma(x)-\int_{\Gamma} n_{\alpha}(x) N_{\alpha \beta}(x) u_{3, \beta}(x) U_{i 3, \gamma}\left(x^{\prime}, x\right) d \Gamma(x) \\
& +\sum_{m=1}^{N+L} \alpha_{\theta}^{m}\left\{\int_{\Gamma} \frac{1}{r} \frac{d r}{d n}\left(\int_{0}^{r(Q)} \frac{h_{\theta \gamma}(r)-h_{\theta \gamma}(\bar{R})}{r} d r\right) d \Gamma\right. \\
& \left.+\int_{\Gamma} \frac{1}{r} \frac{d r}{d n} h_{\theta \gamma}(\bar{R}) \ln (r(Q)) d \Gamma-g \frac{f(\bar{R}) \delta_{\theta \gamma}}{D(1-v) \lambda^{2}}\right\}
\end{aligned}
$$

Equation (4) was written with kernels of boundary integrals differentiated with respect to the field point coordinates. The tangential differential operator can be introduced to reduce the singularities resulting from the differentiation [43]. The final equation for the gradient of the deflection presented in equation (20) is rewritten next with the tangential differential operator:

$$
\begin{aligned}
g u_{3, \gamma}\left(x^{\prime}\right)=\int_{\Gamma}\left\{n_{\alpha}(x) M_{3 \alpha \beta, \gamma}\left(x^{\prime}, x\right) u_{\beta}(x)+Q_{3 \beta}\left(x^{\prime}, x\right) D_{\gamma \beta}\left[u_{3}(x)\right]-U_{3 \beta, \gamma}\left(x^{\prime}, x\right) t_{\beta}(x)\right. \\
\left.-U_{33, \gamma}\left(x^{\prime}, x\right) t_{3}(x)\right\} d \Gamma(x)-\int_{\Gamma} n_{\alpha}(x) N_{\alpha \beta}(x) u_{3, \beta}(x) U_{i 3, \gamma}\left(x^{\prime}, x\right) d \Gamma(x) \\
+\sum_{m=1}^{N+L} \alpha_{\theta}^{m}\left\{\int_{\Gamma} \frac{1}{r} \frac{d r}{d n}\left(\int_{0}^{r(Q)} \frac{h_{\theta \gamma}(r)-h_{\theta \gamma}(\bar{R})}{r} d r\right) d \Gamma\right. \\
\left.+\int_{\Gamma} \frac{1}{r} \frac{d r}{d n} h_{\theta \gamma}(\bar{R}) \ln (r(Q)) d \Gamma-g \frac{f(\bar{R}) \delta_{\theta \gamma}}{D(1-v) \lambda^{2}}\right\}
\end{aligned}
$$

with the tangential differential operator given by,

$$
\mathrm{D}_{\gamma \beta}[f(x)]=n_{\gamma}(x) f_{, \beta}(x)-n_{\beta}(x) f_{, \gamma}(x)
$$


The equation for the generalized plane stress problem is solved once to obtain the inplane force distribution used in the buckling analysis. The BIEs for the plane stress problem are given in the form,

$$
\begin{gathered}
\frac{1}{2} C_{\alpha \beta}\left(x^{\prime}\right) v_{\beta}\left(x^{\prime}\right)+\int_{\Gamma} P_{\alpha \beta}\left(x^{\prime}, x\right) v_{\beta}(x) d \Gamma(x)=\int_{\Gamma} V_{\alpha \beta}\left(x^{\prime}, x\right) p_{\beta}(x) d \Gamma(x) \\
N_{\alpha \gamma}\left(X^{\prime}\right)=S_{\alpha \gamma \kappa \theta} \int_{\Gamma} \sigma_{\kappa \delta \beta}\left(X^{\prime}, x\right) D_{\theta \delta}\left[v_{\beta}(x)\right] d \Gamma(x)-\int_{\Gamma} \sigma_{\beta \alpha \gamma}\left(X^{\prime}, x\right) p_{\beta}(x) d \Gamma(x)
\end{gathered}
$$

where $v_{\beta}$ and $p_{\beta}$ are the displacement and traction in direction $\beta$ of the plane stress problem, respectively. $V_{\alpha \beta}$ and $P_{\alpha \beta}$ represent the displacement and traction in direction $\beta$ due to a unit force in direction $\alpha$, respectively. Equation (23) presents the BIE for stresses at internal points and was written with the tangential differential operator $D_{\alpha \beta}[44]$ and the Hooke tensor for isotropic media $S_{\alpha \beta \gamma \theta}$. The transversal modulus $(\mathrm{G})$ is multiplied by the plate thickness in the generalized plane stress problem.

\section{Numerical Implementation}

In this work, the discretization of the boundary integral equations employed quadratic isoparametric boundary elements and the collocation points were always placed on the boundary. The same mapping function was used for conforming and non-conforming interpolations. The singularity subtraction [45] and the transformation of variable [46] techniques were employed for the Cauchy and weak-type singularities, respectively, when integrations were performed on elements containing the collocation points. The standard Gauss-Legendre scheme was employed for integrations on elements not containing the collocation points.

The buckling problem used equations (10) and (21). The collocation points were placed at nodes for the DBIE, equation (10), in the case of continuous elements and at positions $(-0.67,0.0$, $+0.67)$, in the range $(-1,1)$, in the case of discontinuous elements, i.e., the collocation points were shifted inside the element at the corresponding end where the discontinuity exists. The collocation points were placed inside the boundary elements when using the BIE for the gradient, equation (21), due to continuity requirements. According to this requirement, the collocation points were placed at positions $(-0.67$ and 0.0$)$, in the range $(-1,1)$, in the case of quadratic elements with continuity of displacements/tractions at the last node, which means that it was used to continuous elements or mixed type elements with discontinuity at the first node. On the other hand, the collocation points were placed at positions $(-0.67,0.0,+0.67)$ when the discontinuity of displacements/tractions appears at the last node, which means that it was employed to discontinuous elements or mixed 
elements with discontinuity at the last node. The position of the collocation point of the first node was always shifted inside the boundary elements $(-0.67)$, which means continuous or discontinuous elements had collocations points inside irrespective of the continuity condition at the first node. The RIM considered a uniform distribution of points in the domain whereas the points on the boundary were always placed at the positions of the collocation points.

It is noted that the algebraic manipulations shown in equation (2) introduced one integral performed on the boundary, which is related to the effect of GNL but not with the RIM. The first boundary integral on the left-hand side (LHS) of equation (10) results from equation (2), as well as the second boundary integral on the LHS of equation (21). The discretization of those boundary integrals assumed a constant value along each boundary element for the sum of products between the derivatives of the deflection and the in-plane forces, obtained at the central node. The values of derivatives of the deflection computed at the central node used by the RIM were also used in the computation of those boundary integrals related to equation (2). The treatment for those boundary integrals related to equation (2) was the same adopted in the buckling analysis using DRM and presented in [22].

The domain integration for the RIM involved two numerical integrations which were carried out by using the Gauss-Legendre technique. One integration is carried out in the direction of the radial vector and the other is carried out along each boundary element. In the non-perforated plates, 10 Gauss points were sufficient for the integration along the radial direction while 16 Gauss points were needed in perforated plates. No more than 4 Gauss points were used for the integration along the boundary elements for both types of plates.

The eigenvalue analysis used the basic inverse iteration with the Rayleigh quotient [47] as employed in $[21,22]$ and summarized next:

$$
\begin{gathered}
A x^{(k+1)}=B x^{k} \\
\lambda_{k}=\frac{\left(x^{(k+1)}, x^{k}\right)}{\left(x^{(k+1)}, x^{(k+1)}\right)}
\end{gathered}
$$

The vector $x^{k}$ is related to values of the first derivatives of the deflection at the points used to introduce the RIM. Equation (24) is the representation of the generalized eigenvalue problem and was not used explicitly; rather, the discretized forms of equations (10) and (21) were used, i.e. equations written in matrix form. Starting with an eigenvector $\mathrm{x}^{1}$ (deflection derivatives) with elements equal to 1.0, the values of the displacements and tractions at the nodes of the boundary elements are found with equation (10); these values are introduced in equation (21) to obtain the deflection derivatives (elements of the eigenvector $x^{2}$ ). The lowest eigenvalue at the first iteration step is obtained using equation (25). The iteration procedure continues until the relative difference 
between values of successive eigenvalues is less than $10^{-5}$. The main difference with reference to the formulation using cell integration [21] appears in the need to computing elements $\alpha_{\theta}{ }^{m}$. The elements of $\alpha$ are recalculated at each iteration step according to values of the first derivative of the deflection introduced in equation (7). After the computation of elements $b_{\theta}$, the solution of the system of equations given by equation (8) carries the values of $\alpha_{\theta}{ }^{\mathrm{m}}$ in a similar way done in [22] when the DRM was adopted. The index $\theta$ in elements of $b$ and $\alpha$ is related to directions in the plane of the plate, which means that equations (7) and (8) are used twice and one set of $\alpha$ is obtained for each direction $\theta$ of the plate.

\section{Numerical Tests}

\section{Plates without Holes}

The results of the tests are presented in terms of the buckling parameter $k$, which is a non-dimensional value related to the critical load of plates $\left(N_{c r}\right)$, the length of the plate side (a) and the flexural rigidity (D). The buckling parameter $k$ was obtained according to the following relation:

$$
k=\frac{a^{2} N_{c r}}{\pi^{2} D}
$$

The Young's modulus (E) and Poisson's ratio ( $v$ ) were 206.9 GPa and 0.3, respectively. The default value for the shear parameter $\kappa^{2}$ was $\pi^{2} / 12$ for the Mindlin theory; otherwise, the value 5/6 was assigned when the results were obtained with the Reissner theory. The results are compared with those obtained by using cell integration, the DRM as well as other results from the literature. All boundary element meshes employed double nodes at each corner of the plate.

An initial convergence analysis with the RIM using the radial basis function $f(r)=1+r$ was carried out with a plate simply supported on all sides under in-plane loading in one direction. The discretization used 128 quadratic boundary elements and the number of domain points was increased from 4 to 100 . The results obtained with uniform and non-uniform distributions of points in the domain are presented in Table 1. The intrinsic subroutine Random Number of Intel ${ }^{\circledR}$ Fortran Compiler XE 13.1 was employed to generate the position of the domain points in the non-uniform distribution. Examples of the meshes used are shown in Figure 2 for the uniform and the non-uniform distributions The increase of the number of domain points reduced the difference for the expected values, even for a non-uniform distribution of points in the domain. 
Table 1 - Convergence analysis of SSSS plate under in-plane loading in one direction with uniform and non-uniform domain points distribution, $h / a=0.001$

\begin{tabular}{ccccccc}
\hline BE & DP & $\begin{array}{c}\text { RIM } \\
\text { Uniform }\end{array}$ & $\begin{array}{c}\text { RIM } \\
\text { Non-uniform }\end{array}$ & Analytical & $\begin{array}{c}\text { Diff (\%) } \\
\text { Uniform }\end{array}$ & $\begin{array}{c}\text { Diff (\%) } \\
\text { Non-uniform }\end{array}$ \\
\hline 128 & 4 & 4.3623 & 4.4773 & 4.0000 & 8.30 & 10.66 \\
128 & 9 & 4.1862 & 4.4194 & 4.0000 & 4.45 & 9.49 \\
128 & 16 & 4.1031 & 4.2553 & 4.0000 & 2.51 & 6.00 \\
128 & 25 & 4.0612 & 4.1622 & 4.0000 & 1.51 & 3.90 \\
128 & 36 & 4.0390 & 4.1434 & 4.0000 & 0.97 & 3.46 \\
128 & 49 & 4.0256 & 4.0720 & 4.0000 & 0.64 & 1.77 \\
128 & 64 & 4.0176 & 4.0617 & 4.0000 & 0.44 & 1.52 \\
128 & 81 & 4.0121 & 4.0410 & 4.0000 & 0.30 & 1.02 \\
128 & 100 & 4.0086 & 4.0355 & 4.0000 & 0.21 & 0.88 \\
\hline
\end{tabular}

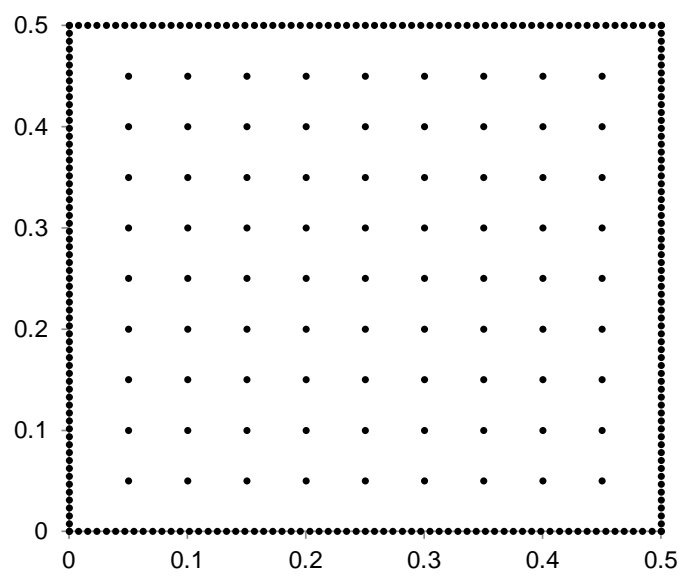

(a)

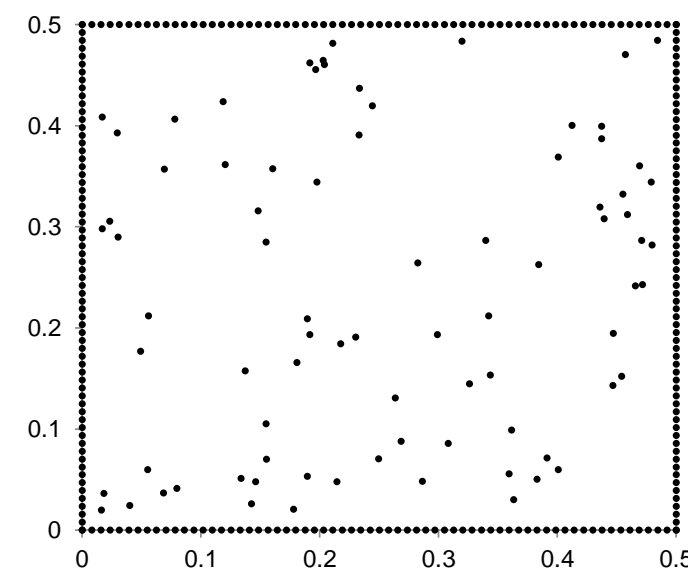

(b)

Figure 2 - Example of discretization for the RIM using a uniform (a) and a non-uniform (b) distribution of domain points.

The results for square non-perforated plates under in-plane loading in one direction are presented in Table 2, while those for loading in both directions are presented in Table 3, and the results for in-plane pure shear load are presented in Table 4. The boundary conditions were simply supported edge (S), clamped edge (C) and free edge (F). The results obtained with simply supported and with clamped edges used the hard condition (rotation restrained in the tangent direction) for comparison with results from the literature. The radial basis function $f(r)=1+r$ was used in all the analyses shown in Tables 2-4, both for the RIM and the DRM, with the following discretizations:

a) Table 2: 256 quadratic boundary elements and 64 internal points, both for the RIM and the DRM.

b) Table 3: 256 quadratic boundary elements and 64 internal points for the RIM, and 384 quadratic boundary elements and 256 internal points for the DRM.

c) Table 4: 256 quadratic boundary elements and 256 internal points for the RIM, and 512 quadratic boundary elements and 256 internal points for the DRM. 
Table 2- Buckling parameter $(k)$ of the first critical load of square plates under in-plane uniaxial loading

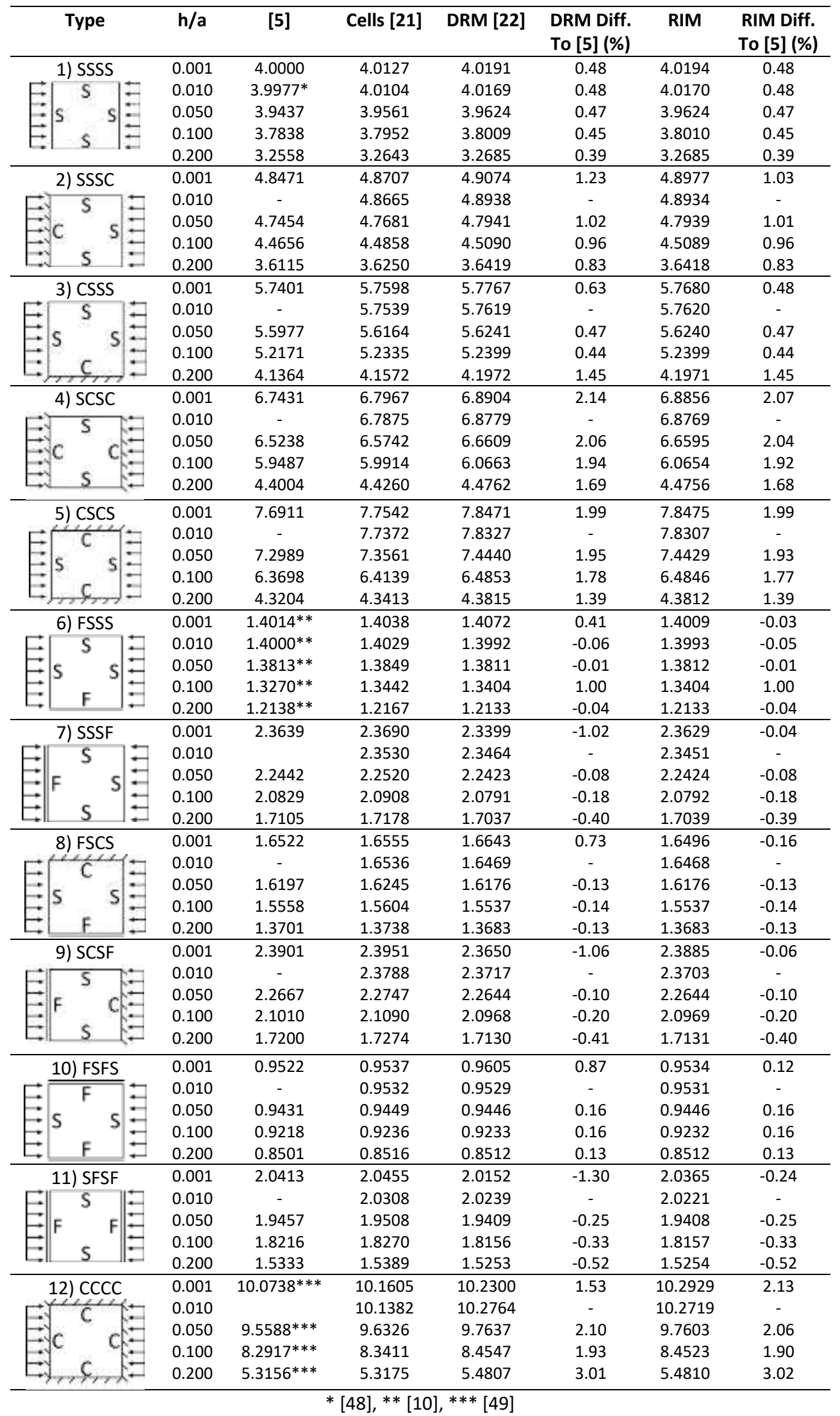


Table 3- Buckling parameter $(k)$ of the first critical load of square plates under in-plane loading in both directions

\begin{tabular}{|c|c|c|c|c|c|c|c|}
\hline Type & h/a & [5] & Cells [21] & DRM [22] & $\begin{array}{l}\text { DRM Diff. } \\
\text { To [5] (\%) }\end{array}$ & RIM & $\begin{array}{l}\text { RIM Diff. } \\
\text { To [5] (\%) }\end{array}$ \\
\hline \multirow{5}{*}{ 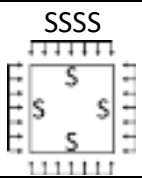 } & 0.001 & 2.0000 & 2.0064 & 1.9971 & $\begin{array}{l}-0.14 \\
\end{array}$ & 2.0006 & 0.03 \\
\hline & 0.005 & 1.9997 & 2.0061 & 1.9986 & -0.05 & 2.0004 & 0.04 \\
\hline & 0.050 & 1.9718 & 1.9782 & 1.9711 & -0.03 & 1.9728 & 0.05 \\
\hline & 0.100 & 1.8919 & 1.8980 & 1.8912 & -0.04 & 1.8929 & 0.05 \\
\hline & 0.150 & 1.7722 & 1.7780 & 1.7717 & -0.03 & 1.7731 & 0.05 \\
\hline \multirow{5}{*}{$\mathrm{E} \mid \begin{array}{ll}\mathrm{SCSF}^{*} \\
\mathrm{~F}^{\mathrm{S}} \mathrm{S}\end{array}$} & 0.001 & 1.1431 & 1.1467 & 1.1509 & 0.68 & 1.1413 & -0.15 \\
\hline & 0.005 & 1.1412 & 1.1449 & 1.1425 & 0.12 & 1.1401 & -0.10 \\
\hline & 0.050 & 1.1119 & 1.1159 & 1.1121 & 0.02 & 1.1105 & -0.13 \\
\hline & 0.100 & 1.0641 & 1.0680 & 1.0637 & -0.03 & 1.0622 & -0.18 \\
\hline & 0.150 & 1.0049 & 1.0087 & 1.0038 & -0.11 & 1.0024 & -0.25 \\
\hline \multirow{5}{*}{ 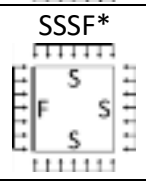 } & 0.001 & 1.0548 & 1.0576 & 1.0597 & 0.46 & 1.0535 & -0.13 \\
\hline & 0.005 & 1.0535 & 1.0564 & 1.0538 & 0.03 & 1.0527 & -0.07 \\
\hline & 0.050 & 1.0322 & 1.0354 & 1.0320 & -0.02 & 1.0313 & -0.09 \\
\hline & 0.100 & 0.9954 & 0.9986 & 0.9947 & -0.07 & 0.9939 & -0.15 \\
\hline & 0.150 & 0.9476 & 0.9507 & 0.9464 & -0.13 & 0.9456 & -0.22 \\
\hline \multirow{5}{*}{ 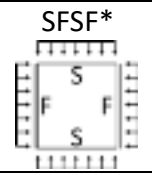 } & 0.001 & 0.9321 & 0.9339 & 0.9413 & 0.98 & 0.9317 & -0.04 \\
\hline & 0.005 & 0.9316 & 0.9335 & 0.9320 & 0.04 & 0.9317 & 0.01 \\
\hline & 0.050 & 0.9207 & 0.9228 & 0.9213 & 0.06 & 0.9206 & -0.01 \\
\hline & 0.100 & 0.8977 & 0.8998 & 0.8980 & 0.03 & 0.8973 & -0.05 \\
\hline & 0.150 & 0.8650 & 0.8671 & 0.8649 & -0.01 & 0.8642 & -0.10 \\
\hline \multirow{5}{*}{ 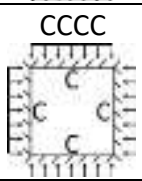 } & 0.001 & $5.3036 * *$ & 5.3482 & 5.3101 & 0.12 & 5.3210 & 0.33 \\
\hline & 0.001 & $5.2970 * * *$ & 5.3460 & 5.3169 & 0.37 & 5.3189 & 0.41 \\
\hline & 0.050 & $5.0840 * *$ & 5.1254 & 5.1021 & 0.36 & 5.1007 & 0.33 \\
\hline & 0.100 & $4.5400 * *$ & 4.5741 & 4.5552 & 0.33 & 4.5538 & 0.30 \\
\hline & 0.150 & $3.8727^{* *}$ & 3.8992 & 3.8847 & 0.31 & 3.8832 & 0.27 \\
\hline
\end{tabular}

Table 4- Buckling parameter $(k)$ of the first critical load of plates under in-plane pure shear loading $\left(\kappa^{2}=5 / 6\right.$,

Reissner)

\begin{tabular}{|c|c|c|c|c|c|c|c|}
\hline Type & h/a & $\begin{array}{l}\text { Value in } \\
\text { reference }\end{array}$ & $\begin{array}{l}\text { Cells } \\
{[21]}\end{array}$ & DRM [22] & $\begin{array}{c}\text { DRM } \\
\text { Diff. to } \\
\text { Ref. (\%) }\end{array}$ & RIM & $\begin{array}{c}\text { RIM } \\
\text { Diff. to } \\
\text { Ref. (\%) }\end{array}$ \\
\hline SSSS & 0.001 & $9.3400(a)$ & 9.4260 & 9.2794 & -0.65 & 9.3577 & 0.19 \\
\hline$\frac{7}{5}$ & 0.01 & 9.3780 (b) & 9.4083 & 9.3295 & -0.52 & 9.3444 & -0.36 \\
\hline$s^{3}$ & 0.05 & & 8.9979 & 8.9250 & - & 8.9381 & - \\
\hline 5 & 0.1 & & 7.9201 & 7.8570 & - & 7.8625 & - \\
\hline$\frac{S}{2-6}$ & 0.20 & & 5.3269 & 5.2745 & - & 5.2728 & - \\
\hline $\mathrm{CCCC}$ & 0.001 & 14.7100 (a) & 14.8702 & 14.7703 & 0.41 & 14.7281 & 0.12 \\
\hline & 0.01 & 14.6155 (b) & 14.8109 & 14.7154 & -0.65 & 14.6780 & 0.43 \\
\hline & 0.05 & & 13.5493 & 13.4506 & - & 13.4255 & - \\
\hline & 0.1 & & 10.8454 & 10.7417 & - & 10.7315 & - \\
\hline & 0.20 & & 6.1662 & 6.3455 & - & 6.3689 & - \\
\hline SCSC & 0.001 & 12.5997 (c) & 12.7360 & 12.8363 & 1.84 & 12.6289 & 0.23 \\
\hline & 0.01 & $12.5800(d)$ & 12.6947 & 12.6850 & -0.08 & 12.5923 & 0.10 \\
\hline & 0.05 & & 11.7923 & 11.7643 & - & 11.6952 & - \\
\hline & 0.1 & & 9.7344 & 9.6784 & - & 9.6444 & - \\
\hline$\frac{5}{2}$ & 0.20 & & 5.8436 & 5.8987 & - & 6.1411 & - \\
\hline SCFC & 0.001 & 8.4289 (e) & 8.5001 & 8.3867 & -0.50 & 8.4011 & -0.33 \\
\hline & 0.01 & & 8.4398 & 8.3653 & - & 8.3727 & - \\
\hline $1 \times C$ & 0.05 & & 7.7706 & 7.6947 & - & 7.7047 & - \\
\hline$y^{2} \mathrm{~s}$ & 0.1 & & 6.4888 & 6.4213 & - & 6.4263 & - \\
\hline$=2$ & 0.20 & & 4.1638 & 4.1184 & - & 4.1183 & - \\
\hline FCFC & 0.001 & $7.4869(\mathrm{e})$ & 7.5437 & 7.4953 & 0.11 & 7.4699 & -0.23 \\
\hline & 0.01 & & 7.4938 & 7.4492 & - & 7.4384 & - \\
\hline & 0.05 & & 6.9230 & 6.8758 & - & 6.8689 & - \\
\hline$x^{2} \mathrm{~F}$ & 0.1 & & 5.8095 & 5.7628 & - & 5.7587 & - \\
\hline$\frac{1}{2 \leftarrow L L}$ & 0.20 & & 3.7634 & 3.7290 & - & 3.7273 & - \\
\hline CSSS & 0.001 & 10.6000 (f) & 10.8349 & 10.8321 & 2.14 & 10.7509 & 1.40 \\
\hline $\overrightarrow{\mathrm{s}}$ & 0.01 & & 10.8083 & 10.7609 & - & 10.7286 & - \\
\hline $5^{3}$ & 0.05 & & 10.2089 & 10.1560 & - & 10.1339 & - \\
\hline & 0.1 & & 8.7375 & 8.6809 & - & 8.6663 & - \\
\hline & 0.20 & & 5.5783 & 5.5194 & - & 5.5151 & - \\
\hline
\end{tabular}

(a) [51], (b) [8], (c) [52], (d) [53], (e) [54], (f) [55]

Table 5 compares the results obtained with other radial basis functions, for problems of in-plane uniaxial loading. The RIM discretizations adopted in this test involved 128 quadratic 
elements and 64 internal points for the functions tested. The functions adopted were $f(r)=1+r, f(r)$ $=1+r+r^{2}+r^{3}$, as well as the thin plate splines $f(r)=r^{2} \ln (r)$, which provided the best results.

Table 5- Buckling parameter $(\mathrm{k})$ of the first critical load of square plates under in-plane uniaxial loading using other approximating functions

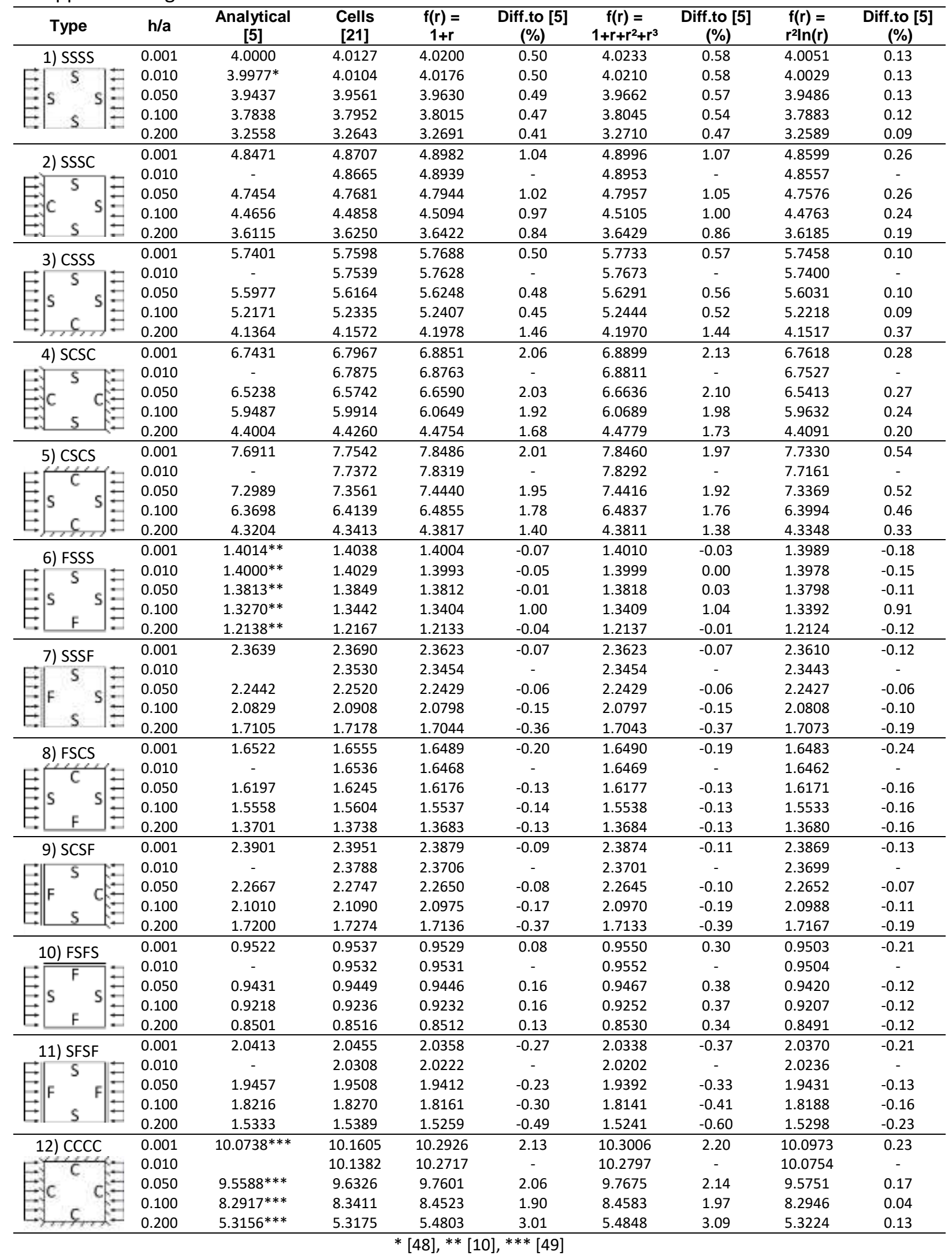




\section{Skew plates}

The results obtained for skew plates under uniaxial loading are presented in Table 6. The discretizations used 256 boundary elements and three sets of domain points were considered: 64 , 100 and 144 . The plates have an aspect ratio of $a / b=1.0$, skew angles $\theta=15^{\circ}, 30^{\circ}$ and $45^{\circ}$, thickness to width ratios $h / b=0.001$ and the radial basis function $f(r)=1+r$ was employed. A sketch of the analyzed plates is presented in Figure 3. The generalized displacements and tractions of the boundary integral equations (10) and (21) had to be written with reference to the normal and the tangential directions at the boundary to introduce the boundary conditions according to the cases presented in the literature.

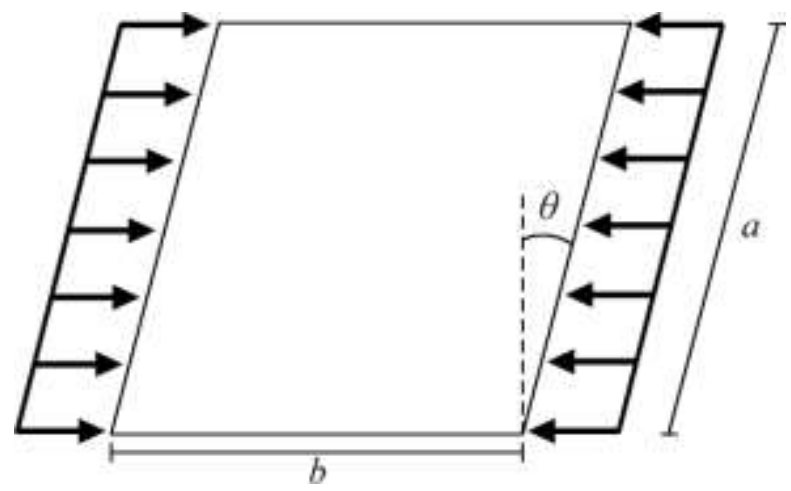

Figure 3 - Skew plate subject to in-plane uniaxial loading

Table 6 - Buckling parameter (k) of the first critical load of SSSS and CCCC skew plates under in-plane uniaxial loading

\begin{tabular}{|c|c|c|c|c|c|c|c|c|}
\hline $\begin{array}{l}\text { Support } \\
\text { condition }\end{array}$ & $\begin{array}{l}\text { Skew } \\
\text { Angle }\end{array}$ & $64 \mathrm{DP}$ & 100 DP & 144 DP & [56] & [57] & [58] & $\begin{array}{c}\text { Diff. (\%) } \\
144 \text { DP to } \\
{[56]}\end{array}$ \\
\hline SSSS & $15^{\circ}$ & 4.4147 & 4.4046 & 4.3997 & 4.3926 & 4.39 & 4.39 & 0.16 \\
\hline $\begin{array}{lll}E & s & \\
E & & \end{array}$ & $30^{\circ}$ & 5.8962 & 5.8792 & 5.8710 & 5.8716 & 5.85 & 5.83 & -0.01 \\
\hline$E$ s & $45^{\circ}$ & 9.7854 & 9.7381 & 9.7154 & 9.8458 & 9.67 & 9.39 & -1.34 \\
\hline $\mathrm{CCCC}$ & $15^{\circ}$ & 11.0966 & 10.9779 & 10.9222 & 10.835 & 10.80 & 10.83 & 0.80 \\
\hline$E \mathrm{E} \quad \mathrm{C}$ & $30^{\circ}$ & 13.9413 & 13.7598 & 13.6737 & 13.538 & 13.50 & 13.54 & 0.99 \\
\hline$E \quad c \quad \exists$ & $45^{\circ}$ & 20.9539 & 20.5744 & 20.3912 & 20.105 & 20.10 & 20.10 & 1.40 \\
\hline
\end{tabular}

Skew plates were also analyzed with other radial approximating functions, for problems of in-plane uniaxial loading. The results are presented in Table 7, using 128 boundary elements and 64 domain points. The plates have an aspect ratio of $\mathrm{a} / \mathrm{b}=1.0$, skew angles $\theta=15^{\circ}, 30^{\circ}$ and $45^{\circ}$ and various thickness to width ratios. 
Table 7- Buckling parameter ( $k$ ) of the first critical load of skew plates under in-plane uniaxial loading using other approximating functions

\begin{tabular}{|c|c|c|c|c|c|c|c|c|}
\hline Type & $h / a$ & [49] & $\begin{array}{c}f(r)= \\
1+r\end{array}$ & $\begin{array}{l}\text { Diff. } \\
(\%)\end{array}$ & $\begin{array}{c}f(r)= \\
1+r+r^{2}+r^{3}\end{array}$ & $\begin{array}{l}\text { Diff. } \\
(\%)\end{array}$ & $\begin{array}{c}f(r)= \\
r^{2} \ln (r)\end{array}$ & $\begin{array}{r}\text { Diff. } \\
(\%)\end{array}$ \\
\hline 1) SSSS & 0.001 & 4.3938 & 4.4161 & 0.50 & 4.4196 & 0.58 & 4.3976 & 0.09 \\
\hline$\theta=15^{\circ}$ & 0.050 & 4.3280 & 4.3481 & 0.46 & 4.3516 & 0.54 & 4.3299 & 0.04 \\
\hline$E \mathrm{~s}$ & 0.100 & 4.1422 & 4.1586 & 0.39 & 4.1618 & 0.47 & 4.1416 & -0.01 \\
\hline$F$ s $\quad s: 7$ & 0.150 & 3.8650 & 3.8765 & 0.30 & 3.8791 & 0.36 & 3.8610 & -0.10 \\
\hline$\Leftrightarrow \quad 5 \quad 7$ & 0.200 & 3.5326 & 3.5391 & 0.19 & 3.5413 & 0.25 & 3.5252 & -0.21 \\
\hline 2) SSSS & 0.001 & 5.8969 & 5.8993 & 0.04 & 5.9036 & 0.11 & 5.8650 & -0.54 \\
\hline$\theta=30^{\circ}$ & 0.050 & 5.7784 & 5.7759 & -0.04 & 5.7801 & 0.03 & 5.7423 & -0.63 \\
\hline$F \mathrm{~s}: 7$ & 0.100 & 5.4617 & 5.4594 & -0.04 & 5.4631 & 0.02 & 5.4273 & -0.63 \\
\hline$F$ is $\quad s: 7$ & 0.150 & 4.9980 & 4.9955 & -0.05 & 4.9984 & 0.01 & 4.9649 & -0.67 \\
\hline$\Leftrightarrow \quad 5 \quad 7$ & 0.200 & 4.4509 & 4.4501 & -0.02 & 4.4524 & 0.03 & 4.4199 & -0.70 \\
\hline 3) SSSS & 0.001 & 10.1032 & 9.7828 & -3.28 & 9.7885 & -3.21 & 9.6827 & -4.34 \\
\hline$\theta=45^{\circ}$ & 0.050 & 9.7063 & 9.4206 & -3.03 & 9.4260 & -2.97 & 9.3240 & -4.10 \\
\hline$E \mathrm{~s}: 7$ & 0.100 & 8.7991 & 8.5910 & -2.42 & 8.5954 & -2.37 & 8.4991 & -3.53 \\
\hline$F$ is $\quad 5: 7$ & 0.150 & 7.5451 & 7.4245 & -1.62 & 7.4277 & -1.58 & 7.3364 & -2.84 \\
\hline$\Leftrightarrow \quad 5 \quad 7$ & 0.200 & 6.1572 & 6.1244 & -0.54 & 6.1267 & -0.50 & 6.0362 & -2.00 \\
\hline 4) $\mathrm{CCCC}$ & 0.001 & 10.8345 & 11.0963 & 2.36 & 11.1049 & 2.43 & 10.8645 & 0.28 \\
\hline$\theta=15^{\circ}$ & 0.050 & 10.2312 & 10.4677 & 2.26 & 10.4756 & 2.33 & 10.2524 & 0.21 \\
\hline$\Leftrightarrow \quad c \quad \Leftrightarrow$ & 0.100 & 8.7741 & 8.9618 & 2.09 & 8.9681 & 2.16 & 8.7797 & 0.06 \\
\hline $\mathrm{CI}$ & 0.150 & 7.0589 & 7.2067 & 2.05 & 7.2102 & 2.10 & 7.2387 & 2.48 \\
\hline$\Leftrightarrow \quad$ c & 0.200 & 5.4913 & 5.6021 & 1.98 & 5.6612 & 3.00 & 5.4940 & 0.05 \\
\hline 5) $\mathrm{CCCC}$ & 0.001 & 13.5377 & 13.9407 & 2.89 & 13.9508 & 2.96 & 13.5914 & 0.39 \\
\hline$\theta=30^{\circ}$ & 0.050 & 12.5711 & 12.9290 & 2.77 & 12.9380 & 2.84 & 12.6095 & 0.30 \\
\hline$\Leftrightarrow \quad c \quad \Leftrightarrow$ & 0.100 & 10.3760 & 10.6495 & 2.57 & 10.6564 & 2.63 & 10.3890 & 0.13 \\
\hline$C=$ & 0.150 & 8.0098 & 8.2089 & 2.43 & 8.2138 & 2.48 & 8.1629 & 1.88 \\
\hline$\Leftrightarrow \quad c \quad \because$ & 0.200 & 6.0328 & 6.2107 & 2.86 & 6.2145 & 2.92 & 6.0265 & -0.10 \\
\hline 6) $\mathrm{CCCC}$ & 0.001 & 20.1115 & 20.9524 & 4.01 & 20.9664 & 4.08 & 20.2413 & 0.64 \\
\hline$\theta=45^{\circ}$ & 0.050 & 17.9652 & 18.6735 & 3.79 & 18.6853 & 3.85 & 18.0584 & 0.52 \\
\hline$\Leftrightarrow \quad c \quad \square$ & 0.100 & 13.6909 & 14.1672 & 3.36 & 14.1750 & 3.42 & 13.7242 & 0.24 \\
\hline $\mathrm{C}=$ & 0.150 & 9.7994 & 10.1088 & 3.06 & 10.1137 & 3.11 & 9.9095 & 1.11 \\
\hline$\Leftrightarrow \quad$ c & 0.200 & 6.9712 & 7.2079 & 3.28 & 7.2111 & 3.33 & 6.9703 & -0.01 \\
\hline 1) FSFS & 0.001 & 1.0674 & 1.0684 & 0.10 & 1.0707 & 0.31 & 1.0655 & -0.18 \\
\hline$\theta=15^{\circ}$ & 0.050 & 1.0523 & 1.0533 & 0.10 & 1.0555 & 0.30 & 1.0505 & -0.17 \\
\hline E $\mathrm{F}$ & 0.100 & 1.0229 & 1.0238 & 0.09 & 1.0259 & 0.29 & 1.0212 & -0.17 \\
\hline 占 $s \quad s:$ & 0.150 & 0.9823 & 0.9826 & 0.03 & 0.9846 & 0.24 & 0.9803 & -0.20 \\
\hline$\Xi F$ & 0.200 & 0.9330 & 0.9328 & -0.02 & 0.9346 & 0.18 & 0.9308 & -0.24 \\
\hline 2) FSFS & 0.001 & 1.5128 & 1.5119 & -0.06 & 1.5146 & 0.12 & 1.5073 & -0.36 \\
\hline$\theta=30^{\circ}$ & 0.050 & 1.4676 & 1.4670 & -0.04 & 1.4697 & 0.14 & 1.4629 & -0.32 \\
\hline E $\mathrm{F}$ & 0.100 & 1.4006 & 1.4004 & -0.01 & 1.4029 & 0.17 & 1.3970 & -0.26 \\
\hline$\Xi / 5 \quad s:$ & 0.150 & 1.3198 & 1.3190 & -0.06 & 1.3213 & 0.12 & 1.3164 & -0.26 \\
\hline$\Xi \quad F$ & 0.200 & 1.2300 & 1.2288 & -0.10 & 1.2308 & 0.07 & 1.2269 & -0.26 \\
\hline 3) FSFS & 0.001 & 2.7443 & 2.7231 & -0.78 & 2.7272 & -0.63 & 2.7307 & -0.50 \\
\hline$\theta=45^{\circ}$ & 0.050 & 2.5762 & 2.5647 & -0.45 & 2.5685 & -0.30 & 2.5724 & -0.15 \\
\hline F: $\mathrm{F}$ & 0.100 & 2.3767 & 2.3683 & -0.35 & 2.3717 & -0.21 & 2.3754 & -0.05 \\
\hline$E$ s & 0.150 & 2.1642 & 2.1564 & -0.36 & 2.1593 & -0.23 & 2.1625 & -0.08 \\
\hline$\Xi \quad F$ & 0.200 & 1.9505 & 1.9434 & -0.37 & 1.9458 & -0.24 & 1.9484 & -0.11 \\
\hline 4) FCFC & 0.001 & 4.2824 & 4.3099 & 0.64 & 4.3116 & 0.68 & 4.2707 & -0.28 \\
\hline$\theta=15^{\circ}$ & 0.050 & 4.1387 & 4.1608 & 0.53 & 4.1623 & 0.57 & 4.1241 & -0.35 \\
\hline$\because \quad F \quad 7$ & 0.100 & 3.7937 & 3.8081 & 0.38 & 3.8094 & 0.41 & 3.7763 & -0.46 \\
\hline$E x \quad c \Xi$ & 0.150 & 3.3391 & 3.3464 & 0.22 & 3.3475 & 0.25 & 3.3200 & -0.57 \\
\hline$B$ F & 0.200 & 2.8620 & 2.8640 & 0.07 & 2.8649 & 0.10 & 2.8426 & -0.68 \\
\hline 5) FCFC & 0.001 & 5.6159 & 5.6399 & 0.42 & 5.6416 & 0.46 & 5.5886 & -0.49 \\
\hline$\theta=30^{\circ}$ & 0.050 & 5.3660 & 5.3803 & 0.27 & 5.3819 & 0.30 & 5.3336 & -0.61 \\
\hline$\Rightarrow \mathrm{F} \quad 7$ & 0.100 & 4.8043 & 4.8131 & 0.18 & 4.8145 & 0.21 & 4.7736 & -0.64 \\
\hline$E x \quad c=$ & 0.150 & 4.1036 & 4.1080 & 0.11 & 4.1092 & 0.14 & 4.0759 & -0.68 \\
\hline$B F$ & 0.200 & 3.4071 & 3.4087 & 0.05 & 3.4097 & 0.08 & 3.3833 & -0.70 \\
\hline 6) FCFC & 0.001 & 8.0948 & 8.0738 & -0.26 & 8.0748 & -0.25 & 8.0173 & -0.97 \\
\hline$\theta=45^{\circ}$ & 0.050 & 7.4670 & 7.4538 & -0.18 & 7.4547 & -0.17 & 7.4071 & -0.81 \\
\hline$G \quad F \quad 7$ & 0.100 & 6.3311 & 6.3232 & -0.13 & 6.3239 & -0.11 & 6.2869 & -0.70 \\
\hline$E x \quad c=$ & 0.150 & 5.1556 & 5.1485 & -0.14 & 5.1491 & -0.13 & 5.1195 & -0.71 \\
\hline$\vec{G} \quad F$ & 0.200 & 4.1438 & 4.1366 & -0.17 & 4.1372 & -0.16 & 4.1121 & -0.77 \\
\hline
\end{tabular}

It should be pointed out that results with the RIM with smaller differences to the expected values can be obtained with the simple radial basis function $(f(r)=1+r)$ using more domain points or with other radial basis functions, such as the thin plate splines, with a lower number of domain points. 


\section{Triangular plates}

Plates of triangular geometry were considered and the results obtained for isosceles and right-angled triangular plates under in-plane loading are presented in Tables 8, 9, 10 and 11. The RIM discretization for triangular plates used 64 quadratic elements in the smaller side of the triangle, with more elements in the bigger sides in a proportional manner and always 64 internal points. The tested plates have various aspect ratios, with angles $\theta=60^{\circ}, 90^{\circ}$ and $120^{\circ}$ for isosceles and $\theta=30^{\circ}, 45^{\circ}$ and $60^{\circ}$ for right-angled triangular plates, several thickness to width ratios and the radial basis function adopted was always $f(r)=1+r$. The notation $\left(S^{*}\right)$ indicates simply supported with soft condition (free rotation in the tangent direction). The generalized displacements and tractions of boundary integral equations (10) and (21) had to be written with reference to the normal and the tangential directions at the boundary to introduce the boundary conditions according to the cases presented in the literature.
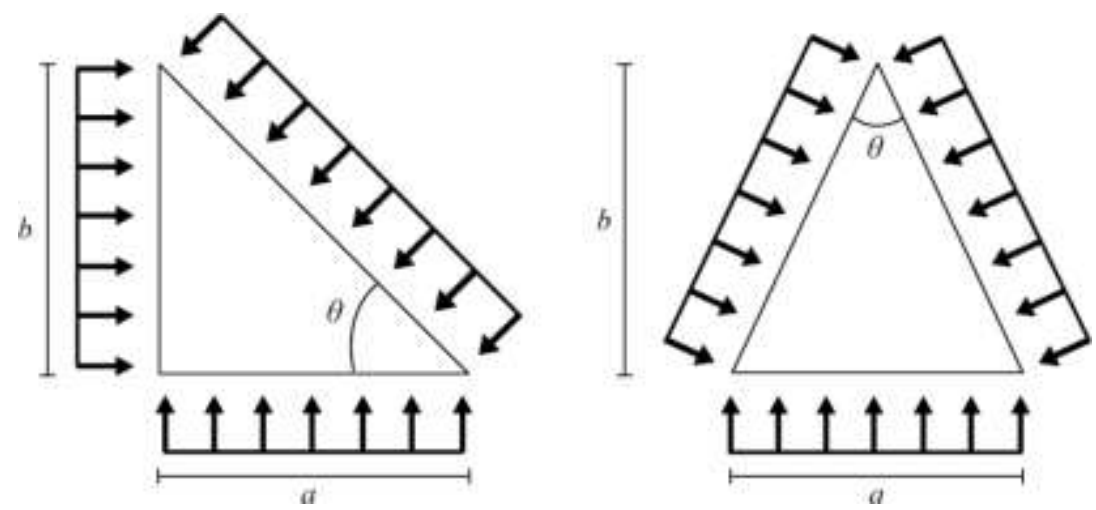

Figure 4 - Triangular plates subject to in-plane uniaxial loading 
Table 8 - Buckling parameter (k) of the first critical load of $S^{*} S^{*} S^{*}, C C C, C C S^{*}, S^{*} S^{*} C$ right-angled triangular plates under in-plane uniaxial loading

\begin{tabular}{|c|c|c|c|c|c|c|c|c|c|c|c|}
\hline \multirow{2}{*}{ Type } & \multirow{2}{*}{$\boldsymbol{\theta}$} & \multicolumn{2}{|c|}{$h / a=0.001$} & \multicolumn{2}{|c|}{$\mathrm{h} / \mathrm{a}=0.05$} & \multicolumn{2}{|c|}{$h / a=0.1$} & \multicolumn{2}{|c|}{$h / a=0.15$} & \multicolumn{2}{|c|}{$\mathrm{h} / \mathrm{a}=0.2$} \\
\hline & & [59] & RIM & [59] & RIM & [59] & RIM & [59] & RIM & [59] & RIM \\
\hline & $30^{\circ}$ & 9.3325 & 9.4151 & 8.3335 & 8.3983 & 6.8123 & 6.8560 & 5.3486 & 5.3759 & 4.1561 & 4.1736 \\
\hline & $45^{\circ}$ & 4.9997 & 5.0352 & 4.6474 & 4.6771 & 4.0887 & 4.1120 & 3.4802 & 3.4967 & 2.9117 & 2.9232 \\
\hline & $60^{\circ}$ & 3.1110 & 3.1398 & 2.9604 & 2.9803 & 2.7049 & 2.7248 & 2.4104 & 2.4266 & 2.1126 & 2.1251 \\
\hline & $30^{\circ}$ & 26.7549 & 27.9761 & 22.0433 & 22.9370 & 14.6481 & 15.1227 & 9.4988 & 9.7508 & 6.4003 & 6.5462 \\
\hline & $45^{\circ}$ & 14.1413 & 14.6309 & 12.6908 & 13.1006 & 9.7909 & 10.0607 & 7.1526 & 7.3187 & 5.2225 & 5.3271 \\
\hline & $60^{\circ}$ & 8.9192 & 9.3258 & 8.3164 & 8.6798 & 6.9494 & 7.2220 & 5.4885 & 5.6775 & 4.2612 & 4.3903 \\
\hline & $30^{\circ}$ & 21.1880 & 21.8895 & 17.6660 & 18.1701 & 12.2456 & 12.5280 & 8.2598 & 8.4079 & 5.7307 & 5.8159 \\
\hline & $45^{\circ}$ & 10.4130 & 10.6436 & 9.4389 & 9.6278 & 7.5524 & 7.7149 & 5.7278 & 5.8762 & 4.3911 & 4.4438 \\
\hline & $60^{\circ}$ & 6.1109 & 6.2680 & 5.7457 & 5.8878 & 4.9924 & 5.0982 & 4.1308 & 4.2095 & 3.3480 & 3.4064 \\
\hline & $30^{\circ}$ & 11.6926 & 11.8491 & 10.3852 & 10.5111 & 8.1952 & 8.2763 & 6.1801 & 6.2294 & 4.6426 & 4.6730 \\
\hline & $45^{\circ}$ & 6.8166 & 6.8982 & 6.3038 & 6.3732 & 5.3722 & 5.4226 & 4.3796 & 4.4148 & 3.5122 & 3.5362 \\
\hline $\mathrm{s}^{*}$ & $60^{\circ}$ & 4.6141 & 4.6940 & 4.3632 & 4.4271 & 3.8710 & 3.9261 & 3.3066 & 3.3486 & 2.7686 & 2.7995 \\
\hline
\end{tabular}

Table 9 - Buckling parameter (k) of the first critical load of CFC, S*FS*, FFC, FCF right-angled triangular plates under in-plane uniaxial loading

\begin{tabular}{|c|c|c|c|c|c|c|c|c|c|c|c|}
\hline \multirow{2}{*}{ Type } & \multirow{2}{*}{$\boldsymbol{\theta}$} & \multicolumn{2}{|c|}{$h / a=0.001$} & \multicolumn{2}{|c|}{$h / a=0.05$} & \multicolumn{2}{|c|}{$h / a=0.1$} & \multicolumn{2}{|c|}{$h / a=0.15$} & \multicolumn{2}{|c|}{$\mathrm{h} / \mathrm{a}=0.2$} \\
\hline & & [59] & RIM & [59] & RIM & [59] & RIM & [59] & RIM & [59] & RIM \\
\hline & $30^{\circ}$ & 4.4560 & 4.4545 & 4.1520 & 4.1504 & 3.6534 & 3.6495 & 3.1102 & 3.1050 & 2.6094 & 2.6040 \\
\hline & $45^{\circ}$ & 2.5324 & 2.5302 & 2.4160 & 2.4142 & 2.2226 & 2.2199 & 1.9931 & 1.9897 & 1.7591 & 1.7555 \\
\hline & $60^{\circ}$ & 1.4855 & 1.4850 & 1.4382 & 1.4380 & 1.3611 & 1.3604 & 1.2656 & 1.2644 & 1.1616 & 1.1601 \\
\hline & $30^{\circ}$ & 0.5678 & 0.5667 & 0.5155 & 0.5154 & 0.4616 & 0.4617 & 0.4084 & 0.4087 & 0.3579 & 0.3584 \\
\hline & $45^{\circ}$ & 0.3683 & 0.3689 & 0.3473 & 0.3471 & 0.3241 & 0.3241 & 0.3009 & 0.3010 & 0.2781 & 0.2783 \\
\hline & $60^{\circ}$ & 0.1893 & 0.1890 & 0.1798 & 0.1793 & 0.1691 & 0.1690 & 0.1587 & 0.1587 & 0.1483 & 0.1484 \\
\hline & $30^{\circ}$ & 0.5146 & 0.5166 & 0.5067 & 0.5067 & 0.4963 & 0.4961 & 0.4837 & 0.4834 & 0.4668 & 0.4667 \\
\hline & $45^{\circ}$ & 0.4826 & 0.4825 & 0.4740 & 0.4738 & 0.4636 & 0.4632 & 0.4511 & 0.4508 & 0.4371 & 0.4368 \\
\hline & $60^{\circ}$ & 0.4359 & 0.4355 & 0.4287 & 0.4282 & 0.4192 & 0.4188 & 0.4083 & 0.4079 & 0.3958 & 0.3956 \\
\hline FCF & $30^{\circ}$ & 1.8749 & 1.8728 & 1.8013 & 1.7995 & 1.6945 & 1.6926 & 1.5697 & 1.5673 & 1.4367 & 1.4341 \\
\hline & $45^{\circ}$ & 0.9923 & 0.9913 & 0.9639 & 0.9633 & 0.9261 & 0.9252 & 0.8814 & 0.8805 & 0.8327 & 0.8316 \\
\hline$F \theta$ & $60^{\circ}$ & 0.6250 & 0.6244 & 0.6127 & 0.6120 & 0.5955 & 0.5949 & 0.5752 & 0.5746 & 0.5525 & 0.5518 \\
\hline
\end{tabular}


Table 10 - Buckling parameter ( $\mathrm{k}$ ) of the first critical load of $\mathrm{S}^{*} \mathrm{~S}^{*} \mathrm{~S}^{*}, \mathrm{CCC}, \mathrm{S}^{*} \mathrm{CC}, \mathrm{CS} \mathrm{S}^{*}$ isosceles triangular plates under in-plane uniaxial loading

\begin{tabular}{|c|c|c|c|c|c|c|c|c|c|c|c|}
\hline \multirow{2}{*}{ Type } & \multirow{2}{*}{$\boldsymbol{\theta}$} & \multicolumn{2}{|c|}{$h / a=0.001$} & \multicolumn{2}{|c|}{$h / a=0.05$} & \multicolumn{2}{|c|}{$h / a=0.1$} & \multicolumn{2}{|c|}{$h / a=0.15$} & \multicolumn{2}{|c|}{$\mathrm{h} / \mathrm{a}=0.2$} \\
\hline & & [59] & RIM & [59] & RIM & [59] & RIM & [59] & RIM & [59] & RIM \\
\hline & $60^{\circ}$ & 5.3329 & 5.3749 & 4.9457 & 4.9822 & 4.3247 & 4.3518 & 3.6499 & 3.6688 & 3.0271 & 3.0403 \\
\hline & $90^{\circ}$ & 9.9986 & 10.0988 & 8.8591 & 8.9391 & 7.1671 & 7.2183 & 5.5697 & 5.6016 & 4.2908 & 4.3110 \\
\hline & $120^{\circ}$ & 21.8916 & 22.1789 & 17.6066 & 17.8785 & 12.4002 & 12.5449 & 8.4705 & 8.5480 & 5.9041 & 5.9484 \\
\hline & $60^{\circ}$ & 14.8340 & 15.3950 & 13.2452 & 13.7094 & 10.1189 & 10.4199 & 7.3314 & 7.5147 & 5.3228 & 5.4378 \\
\hline & $90^{\circ}$ & 28.2820 & 29.7982 & 23.0740 & 24.1685 & 15.1120 & 15.6863 & 9.7033 & 10.0070 & 6.4984 & 6.6740 \\
\hline & $120^{\circ}$ & 64.1827 & 72.7347 & 42.9529 & 47.2623 & 21.8710 & 23.4636 & 12.1717 & 12.8250 & 7.5402 & 7.8525 \\
\hline & $60^{\circ}$ & 10.6050 & 10.8488 & 9.6030 & 9.8058 & 7.6996 & 7.8365 & 5.8629 & 5.9493 & 4.4318 & 4.4866 \\
\hline & $90^{\circ}$ & 18.6660 & 19.1886 & 15.9231 & 16.3164 & 11.4322 & 11.6562 & 7.8842 & 8.0069 & 5.5366 & 5.6071 \\
\hline & $120^{\circ}$ & 39.8561 & 42.0908 & 29.6714 & 31.0230 & 17.3888 & 17.9571 & 10.4138 & 10.6617 & 6.7187 & 6.8393 \\
\hline $5 *$ & $60^{\circ}$ & 7.5737 & 7.6761 & 6.9465 & 7.0339 & 5.8285 & 5.8912 & 4.6707 & 4.7129 & 3.6889 & 3.7170 \\
\hline & $90^{\circ}$ & 15.6138 & 15.9233 & 13.3074 & 13.5364 & 9.8413 & 9.9760 & 7.0017 & 7.0785 & 5.0409 & 5.0862 \\
\hline$S_{C}{ }^{2}$ & $120^{\circ}$ & 37.0388 & 38.3433 & 26.8880 & 27.7928 & 16.1176 & 16.5120 & 9.8505 & 10.0286 & 6.4487 & 6.5374 \\
\hline
\end{tabular}

Table 11 - Buckling parameter ( $k$ ) of the first critical load of FCC, FS*S*, CFF, FCF isosceles triangular plates under in-plane uniaxial loading

\begin{tabular}{|c|c|c|c|c|c|c|c|c|c|c|c|}
\hline \multirow{2}{*}{ Type } & \multirow{2}{*}{$\boldsymbol{\theta}$} & \multicolumn{2}{|c|}{$h / a=0.001$} & \multicolumn{2}{|c|}{$h / a=0.05$} & \multicolumn{2}{|c|}{$h / a=0.1$} & \multicolumn{2}{|c|}{$h / a=0.15$} & \multicolumn{2}{|c|}{$h / a=0.2$} \\
\hline & & [59] & RIM & [59] & RIM & [59] & RIM & [59] & RIM & [59] & RIM \\
\hline FCC & $60^{\circ}$ & 3.8151 & 3.8045 & 3.5641 & 3.5529 & 3.1499 & 3.1369 & 2.6914 & 2.6785 & 2.2649 & 2.2530 \\
\hline & $90^{\circ}$ & 5.0644 & 5.0610 & 4.6855 & 4.6812 & 4.0671 & 4.0597 & 3.4081 & 3.3997 & 2.8168 & 2.8087 \\
\hline & $120^{\circ}$ & 8.3586 & 8.3759 & 7.5412 & 7.5511 & 6.2480 & 6.2480 & 4.9769 & 4.9727 & 3.9211 & 3.9160 \\
\hline FS & $60^{\circ}$ & 0.8469 & 0.8456 & 0.8012 & 0.8011 & 0.7475 & 0.7478 & 0.6897 & 0.6902 & 0.6305 & 0.6314 \\
\hline & $90^{\circ}$ & 0.7389 & 0.7377 & 0.6752 & 0.6753 & 0.6097 & 0.6100 & 0.5454 & 0.5459 & 0.4843 & 0.4850 \\
\hline & $120^{\circ}$ & 0.6523 & 0.6364 & 0.5037 & 0.5036 & 0.4142 & 0.4146 & 0.3446 & 0.3454 & 0.2890 & 0.2899 \\
\hline CFF & $60^{\circ}$ & 0.7039 & 0.7034 & 0.6886 & 0.6881 & 0.6684 & 0.6679 & 0.6447 & 0.6441 & 0.6184 & 0.6178 \\
\hline & $90^{\circ}$ & 1.9846 & 1.9827 & 1.8986 & 1.8974 & 1.7789 & 1.7772 & 1.6410 & 1.6389 & 1.4962 & 1.4940 \\
\hline$c$ & $120^{\circ}$ & 5.3448 & 5.3480 & 4.9338 & 4.9367 & 4.3232 & 4.3214 & 3.6721 & 3.6678 & 3.0680 & 3.0630 \\
\hline F( & $60^{\circ}$ & $\begin{array}{c}1,2269 \\
0.7396^{*}\end{array}$ & 0.7033 & 1.1870 & 0.6880 & 1.1335 & 0.6678 & 1.0716 & 0.6440 & 1.0048 & 0.6177 \\
\hline$F$ & $90^{\circ}$ & $\begin{array}{c}1.7305 \\
0.9650 *\end{array}$ & 0.9642 & 1.6575 & 0.9393 & 1.5639 & 0.9059 & 1.4538 & 0.8662 & 1.3099 & 0.8209 \\
\hline $\mathrm{F}$ & $120^{\circ}$ & $\begin{array}{c}2.3264 \\
1.3243^{*}\end{array}$ & 1.2964 & 2.1939 & 1.2694 & 1.9462 & 1.1944 & 1.4136 & 1.0338 & 1.0252 & 0.8069 \\
\hline
\end{tabular}

An increase in the differences in the results was obtained for the case FCF in Table 11 when the results obtained with the RIM were compared with results obtained in [59]. Another study by the same author [60] but using the classical plate theory and published years later presented values similar to those obtained here with the RIM, and they were included here for the lowest ratio as usual in the 
literature when results obtained with the classical plate theory are compared with Reissner-Mindlin plate models.

\section{Plates with Holes}

The problem of a plate containing a square hole, shown in Figure 5, was studied next. The plate was uniformly compressed along opposite edges, and equations (22) and (23) were used to obtain in-plane forces at the internal points used for the RIM. The values adopted here for Young's modulus (E) and Poisson's ratio ( $v$ ) were $206.9 \mathrm{GPa}$ and 0.3 , respectively. The shear parameter $\left(\kappa^{2}\right)$ related to the effect of the shear deformation was equal to $\pi^{2} / 12$, and the edges were considered simply supported under the hard condition. The lengths of the side of the square hole and the side of the square plate are $d$ and $a$. The buckling parameter versus thickness to length ratio $(\mathrm{h} / \mathrm{b})$ and the normalized square hole dimension $(\mathrm{d} / \mathrm{b})$ are presented in Tables 12 through 14 . The results are compared with those obtained when the cell integration [21] and the DRM [61] were used. The radial basis function $(1+r)$ was used in analyses with DRM and RIM. The meshes used in the analyses of each plate are presented in Table 15.

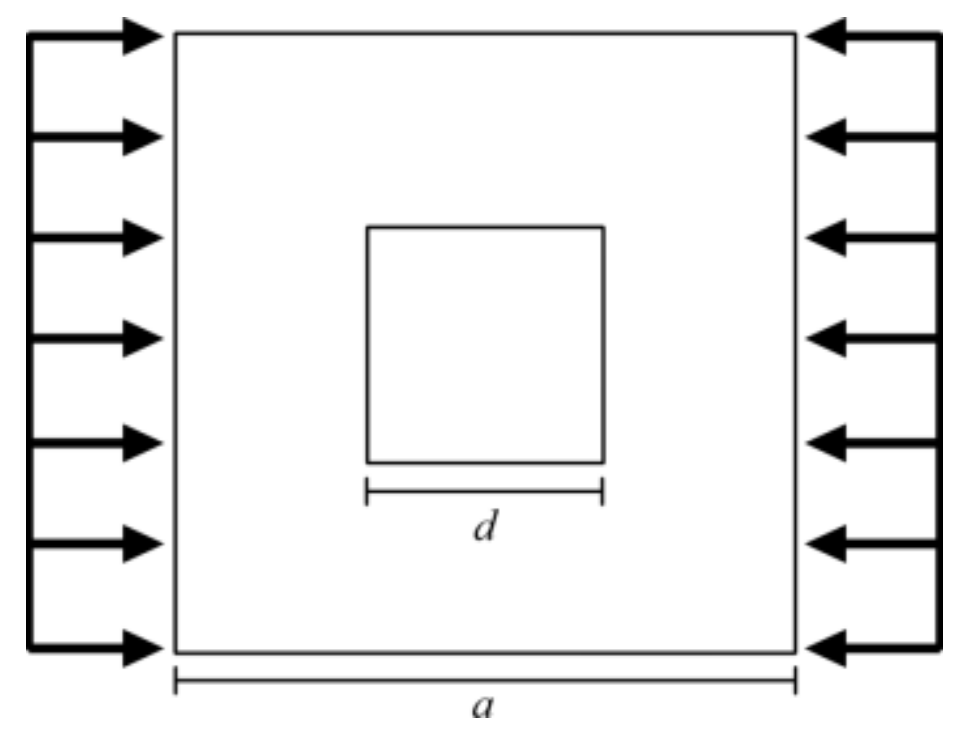

Figure 5 - Perforated plate with central square hole subject to in-plane uniaxial loading

Table 12 - Plate with square hole, $\mathrm{h} / \mathrm{a}=0.001$ and $\mathrm{h} / \mathrm{a}=0.01$

\begin{tabular}{ccccccccc}
\hline BE & DP & d/a & DRM [61] & Cells [21] & RIM & DRM [61] & Cells [21] & RIM \\
\hline 480 & 864 & 0.1 & 3.7946 & 3.7994 & 3.7898 & 3.7879 & 3.7932 & 3.7878 \\
480 & 836 & 0.2 & 3.4397 & 3.4494 & 3.4524 & 3.4296 & 3.4412 & 3.4377 \\
480 & 880 & 0.3 & 3.1713 & 3.1883 & 3.1839 & 3.1575 & 3.1782 & 3.1769 \\
480 & 936 & 0.4 & 2.9998 & 3.0297 & 3.0471 & 2.9810 & 3.0153 & 3.0121 \\
480 & 896 & 0.5 & 2.9069 & 2.9310 & 2.9236 & 2.8881 & 2.9096 & 2.8996 \\
480 & 924 & 0.6 & 2.8186 & 2.8664 & 2.8591 & 2.8175 & 2.8352 & 2.8348 \\
480 & 984 & 0.7 & $2.8168 *$ & 2.8449 & 2.8544 & 2.8001 & 2.7998 & 2.7628 \\
\hline
\end{tabular}

${ }^{*} 1024$ boundary elements along the external boundary and 256 along the internal boundary 
Table 13 - Plate with square hole, $\mathrm{h} / \mathrm{a}=0.05$ and $\mathrm{h} / \mathrm{a}=0.1$

\begin{tabular}{ccccccccc}
\hline BE & DP & d/a & DRM [61] & Cells [21] & RIM & DRM [61] & Cells [21] & RIM \\
\hline 480 & 864 & 0.1 & 3.7248 & 3.7313 & 3.7267 & 3.5722 & 3.5819 & 3.5765 \\
480 & 836 & 0.2 & 3.3602 & 3.3747 & 3.3680 & 3.2140 & 3.2344 & 3.2261 \\
480 & 880 & 0.3 & 3.0774 & 3.1034 & 3.0999 & 2.9207 & 2.9577 & 2.9517 \\
480 & 936 & 0.4 & 2.8781 & 2.9207 & 2.9145 & 2.6898 & 2.7495 & 2.7405 \\
480 & 896 & 0.5 & 2.7562 & 2.7820 & 2.7678 & 2.5333 & 2.5670 & 2.5470 \\
480 & 924 & 0.6 & 2.6392 & 2.6625 & 2.6491 & 2.3596 & 2.3884 & 2.3643 \\
480 & 984 & 0.7 & 2.5388 & 2.5629 & 2.5359 & 2.2438 & 2.2716 & 2.2518 \\
\hline
\end{tabular}

Table 14 - Plate with square hole, $\mathrm{h} / \mathrm{a}=0.2$

\begin{tabular}{cccccc}
\hline BE & DP & d/a & DRM [61] & $\begin{array}{c}\text { Cells [21] } \\
\text { C.0.2 }\end{array}$ & RIM \\
\hline 480 & 864 & 0.1 & 3.0712 & 3.1043 & 3.0776 \\
480 & 836 & 0.2 & 2.7135 & 2.8052 & 2.7841 \\
480 & 880 & 0.3 & 2.3788 & 2.5138 & 2.4906 \\
480 & 936 & 0.4 & 2.0842 & 2.2235 & 2.2041 \\
480 & 896 & 0.5 & 1.9152 & 1.7185 & 1.8769 \\
480 & 924 & 0.6 & 1.4944 & 1.1755 & 1.4777 \\
480 & 984 & 0.7 & 0.8317 & 0.7263 & 0.8144 \\
\hline
\end{tabular}

Table 15 - Discretization adopted in the simulations

\begin{tabular}{|c|c|c|c|c|c|c|c|c|}
\hline \multirow{3}{*}{$d / a$} & \multicolumn{4}{|c|}{ DRM } & \multicolumn{2}{|c|}{ Cells } & \multicolumn{2}{|c|}{ RIM } \\
\hline & \multirow{2}{*}{$\begin{array}{c}\text { Domain } \\
\text { Points }\end{array}$} & \multicolumn{3}{|c|}{ Boundary Elements } & \multirow{2}{*}{$\begin{array}{c}\text { Domain } \\
\text { Cells }\end{array}$} & \multirow{2}{*}{$\begin{array}{l}\text { Boundary } \\
\text { Elements }\end{array}$} & \multirow{2}{*}{$\begin{array}{l}\text { Domain } \\
\text { Points }\end{array}$} & \multirow{2}{*}{$\begin{array}{l}\text { Boundary } \\
\text { Elements }\end{array}$} \\
\hline & & $h / a=0.001$ & $0.01 \leq h / a \leq 0.1$ & $\mathrm{~h} / \mathrm{a}=0.2$ & & & & \\
\hline 0.1 & 1564 & 480 & 480 & 480 & 6336 & 704 & 864 & 480 \\
\hline 0.2 & 1500 & 480 & 480 & 480 & 6144 & 768 & 836 & 480 \\
\hline 0.3 & 1568 & 480 & 480 & 480 & 5824 & 832 & 880 & 480 \\
\hline 0.4 & 1536 & 480 & 480 & 480 & 5376 & 896 & 936 & 480 \\
\hline 0.5 & 1533 & 480 & 480 & 1280 & 4800 & 960 & 896 & 480 \\
\hline 0.6 & 1548 & 480 & 480 & 1280 & 4096 & 1024 & 924 & 480 \\
\hline 0.7 & 1632 & 1280 & 480 & 1280 & 3264 & 1088 & 984 & 480 \\
\hline
\end{tabular}

The processing times for each technique are discussed below for the cell integration, the DRM and the RIM. As an illustration, the processing times for the case $h / a=0.2$ and $d / a=0.5$ were as follows:
a) Cell integration- 13 min $56 \mathrm{sec}$ (960 boundary elements and 4800 domain cells)
b) DRM - 38 min $02 \mathrm{sec}$ (1280 boundary elements and 1533 domain points)
c) RIM - 50 min $45 \mathrm{sec}$ (480 boundary elements, 896 domain points)

All the analyses used the Intel Fortran Compiler on Windows 7 with the compiler set to the Release Mode using default values. The computer had an Intel i7-4790 (3.6 GHz) and $16 \mathrm{~Gb}$ of RAM. 


\section{Conclusions}

This paper presented a BEM formulation with the RIM for the buckling of plates with shear deformation. The results obtained with the RIM were, in the greatest majority of cases, more accurate than the results obtained by the DRM and by using domain cells. The total number of approximation points used in the RIM, considering the sum of boundary and internal points, was also lower than the number of points for the DRM. On the other hand, the need to evaluate integrals in the radial direction and along the boundary meant a higher computing time.

Another point that was noted in this work, related to numerical integration, was that the use of 4 Gauss points for each quadratic boundary element was sufficient for the accuracy obtained by the RIM. However, the radial integration has to be carried out for each of the directions passing through the poles of the radial function, for each Gauss point along the boundary. Because of this, the solution time of the DRM was lower than for the RIM, even using a higher number of boundary and domain points. For problems with non-perforated plates, the radial integrals could be calculated with 10 Gauss points, with sufficient accuracy. However, for perforated plates, it was necessary to subdivide the boundary elements into 3 sub-elements and to use 16 Gauss points in each subelement to obtain the desired accuracy. The reason could be the complexity of the terms involved in the radial integral for perforated plates.

Parallel processing was implemented for some stages of the computer code developed for the RIM, but the processing time was still higher than the DRM code which was kept with sequential processing.

In conclusion, the RIM presents advantages related to its ease of implementation and in the opportunity use different radial basis functions without the need to derive particular solutions. However, it does require a much higher computing time for its processing. It was also verified that the radial integrals need to be computed accurately, independent of the complexity of the domain loads, to obtain good convergence of the numerical solutions.

\section{References}

[1] Love AEH. The small free vibrations and deformation of a thin elastic shell. Philosophical Transactions of the Royal Society A, Vol. 179, pp. 491-546, 1888.

[2] Reissner $E$. The effect of transverse shear deformation on the bending of elastic plates. Journal of Applied Mechanics, Vol. 12, pp. A69-A77, 1945. 
[3] Mindlin RD. Influence of rotatory inertia and shear on flexural motions of isotropic elastic plates. Journal of Applied Mechanics, Vol. 18, pp. 31-38, 1951.

[4] Timoshenko SP, Woinowsky-Krieger S. Theory of Plates and Shells. 2nd ed. New York: McGrawHill Book Company; 1959.

[5] Hosseini-Hashemi S, Khorshidi K, Amabili M. Exact solution for linear buckling of rectangular Mindlin plates. Journal of Sound and Vibration, Vol. 315, pp. 318-342, 2008.

[6] El-Sawy KM, Nazmy AS. Effect of aspect ratio on the elastic buckling of uniaxially loaded plates with eccentric holes. Thin-Walled Structures, Vol. 39, pp. 983-998, 2001.

[7] Reddy J. Energy Principles and Variational Methods in Applied Mechanics. 2nd ed. John Wiley \& Sons, NY, 2002.

[8] Bui TQ, Nguyen MN, Zhang C. Buckling analysis of Reissner-Mindlin plates subjected to in-plane edge loads using a shear-locking-free and meshfree method. Engineering Analysis with Boundary Elements, Vol. 35, pp. 1038-1053, 2011.

[9] Katsikadelis JT, Babouskos N. The post-buckling analysis of plates. A BEM based meshless variational solution. Facta Universitatis, Series Mechanics, Automatic Control and Robotics, Vol. 6, pp. 113-118, 2007.

[10] Mizusawa T. Buckling of rectangular Mindlin plates with tapered thickness by the spline strip method, International Journal of Solids and Structures, Vol. 30, pp. 1663-1677, 1993.

[11] Dawe DJ, Roufaeil OL. Buckling of rectangular Mindlin plates. Computers \& Structures, Vol. 15, pp. 461-471, 1982.

[12] Brown CJ, Yettram AL. The elastic stability of square perforated plates under combinations of bending, shear and direct load. Thin-Walled Structures, Vol. 4, pp. 239-246, 1986.

[13] Brebbia CA, Telles JCF and Wrobel, LC. Boundary Element Techniques: Theory and Applications in Engineering. Berlin. Springer-Verlag, 1984.

[14] Nardini D, Brebbia CA. A new approach to free vibration analysis using boundary elements. Applied Mathematical Modelling, Vol. 7, pp. 157-162, 1983.

[15] Partridge PW, Brebbia CA, Wrobel LC. The Dual Reciprocity Boundary Element Method. Springer Science \& Business Media, 1992.

[16] Nowak AJ, Brebbia CA. The multiple reciprocity method: A new approach for transforming domain integrals into the boundary. Engineering Analysis with Boundary Elements, Vol. 6, pp. 164167, 1989.

[17] Yiotis A.J, Katsikadelis JT. The meshless analog equation method for the solution of plate problems. Proceedings of the 6th GRACM International Congress on Computational Mechanics, Thessaloniki, Greece. 2008.

[18] Gao XW. The radial integration method for evaluation of domain integrals with boundary-only discretization. Engineering Analysis with Boundary Elements, Vol. 26, pp. 905-916, 2002. 
[19] Wen PH, Aliabadi MH, Rooke DP. A new method for transformation of domain integrals to boundary integrals in boundary element method. Communications in Numerical Methods in Engineering, Vol. 14, pp. 1055-1065, 1998.

[20] Purbolaksono J, Aliabadi MH. Buckling analysis of shear deformable plates by boundary element method. International Journal for Numerical Methods in Engineering, Vol. 62, pp. 537-563, 2005.

[21] Soares Jr RA, Palermo Jr L. Effect of shear deformation on the buckling parameter of perforated and non-perforated plates studied using the boundary element method. Engineering Analysis with Boundary Elements, Vol. 85, pp. 57-69, 2017.

[22] Soares Jr RA, Palermo Jr L, Wrobel LC. Application of the dual reciprocity method for the buckling analysis of plates with shear deformation. Engineering Analysis with Boundary Elements, Vol. 106, pp. 427-439, 2019.

[23] Albuquerque EL, Sollero P, Portilho de Paiva W. The radial integration method applied to dynamic problems of anisotropic plates. Communications in Numerical Methods in Engineering, Vol. 23, pp. 805-818, 2007.

[24] Venturini WS. Application of the boundary element formulation to solve geomechanical problems. PhD Thesis, University of Southampton, Southampton, 1982.

[25] Gao XW. Boundary only integral equations in boundary element analysis. Proceedings of the International Conference on Boundary Element Techniques, Rutgers University, NJ, USA, pp. 39-46, 2001.

[26] Gao XW. A meshless BEM for isotropic heat conduction problems with heat generation and spatially varying conductivity. International Journal for Numerical Methods in Engineering, Vol. 66, pp. 1411-1431, 2006.

[27] Yang K, Gao XW. Radial integration BEM for transient heat conduction problems. Engineering Analysis with Boundary Elements, Vol. 34, pp. 557-563, 2010.

[28] Wang J, Peng HF, Yang K. Radial integration boundary element method for heat conduction problems with convective heat transfer boundary. Numerical Heat Transfer, Part B: Fundamentals, Vol. 72, pp. 300-310, 2017.

[29] AL-Jawary $M$. The radial integration boundary integral and integro-differential equation methods for numerical solution of problems with variable coefficients. PhD Thesis, School of Engineering and Design, Brunel University London, 2012.

[30] Peng HF, Yang K, Cui M, Gao XW. Radial integration boundary element method for solving twodimensional unsteady convection-diffusion problem. Engineering Analysis with Boundary Elements, Vol. 102, pp. 39-50, 2019.

[31] Gao XW, Zhang C, Guo, L. Boundary-only element solutions of 2D and 3D nonlinear and nonhomogeneous elastic problems. Engineering Analysis with Boundary Elements, Vol. 31, pp. $974-$ 982, 2007.

[32] Gao XW. A boundary element method without internal cells for two-dimensional and threedimensional elastoplastic problems. Journal of Applied Mechanics, Vol. 69, pp. 154-160, 2002. 
[33] Yang K, Feng WZ, Li J, Gao XW. New analytical expressions in radial integration BEM for stress computation with several kinds of variable coefficients. Computer Methods in Applied Mechanics and Engineering, Vol. 289, pp. 44-59, 2015.

[34] Qu S, Li S, Chen HR, Qu Z. Radial integration boundary element method for acoustic eigenvalue problems. Engineering Analysis with Boundary Elements, Vol. 37, pp. 1043-1051, 2013.

[35] Zheng B, Gao XW, Zhang C. Radial integration BEM for vibration analysis of two-and threedimensional elasticity structures. Applied Mathematics and Computation, Vol. 277, pp. 111-126, 2016.

[36] Doval PCM, Albuquerque EL, Sollero P. Stability analysis of elastic plates under non-uniform stress fields by the boundary element method. Mecânica Computacional, Vol. 29, pp. 699-705, 2010.

[37] Santana AP. Formulação do método dos elementos de contorno para análise de placas espessas isotrópicas e ortotrópicas. PhD Thesis, University of Brasília, Brasília, Brazil, 2014 (in Portuguese).

[38] Doval PCM. Análise de estabilidade de placas de materiais compósitos laminados usando o método dos elementos de contorno. PhD Thesis, State University of Campinas, Campinas, Brazil, 2013 (in Portuguese).

[39] Albuquerque EL, Aliabadi MH. A boundary element formulation for boundary only analysis of thin shallow shells. Computer Modeling in Engineering \& Sciences, Vol. 29, pp. 63-73, 2008.

[40] Bui HD. Some remarks about the formulation of three-dimensional thermoelastoplastic problems by integral equations. International Journal of Solids and Structures, Vol. 14, pp. 935-939, 1978.

[41] Telles JCF, Brebbia CA. On the application of the boundary element method to plasticity. Applied Mathematical Modelling, Vol. 3, pp. 466-470, 1979.

[42] Guiggiani MG, Gigante A. A general algorithm for multidimensional Cauchy principal value integrals in the boundary element method. Journal of Applied Mechanics, Vol. 57, pp. 906-915, 1990.

[43] Palermo Jr L. The tangential differential operator applied to a stress boundary integral equation for plate bending including the shear deformation effect. Engineering Analysis with Boundary Elements, Vol. 36, pp. 1213-1225, 2012.

[44] Bonnet M. Boundary Integral Equation Methods for Solids and Fluids. Chichester. John Wiley \& Sons Ltd; 1999.

[45] Wrobel LC. The Boundary Element Method: Applications in Thermo-Fluids and Acoustics, Chichester. John Wiley \& Sons Ltd., 2002.

[46] Telles JCF. A self-adaptive coordinate transformation for efficient numerical evaluation of general boundary element integrals, International Journal for Numerical Methods in Engineering, Vol. 24, pp. 959-973, 1987.

[47] Wilkinson JH. The Algebraic Eigenvalue Problem. London: Oxford University Press, 1972.

[48] Hosseini-Hashemi S, Atashipour SR, Fadaee M. On the buckling analysis of isotropic, transversely isotropic, and laminated rectangular plates via Reddy plate theory: an exact closed-form procedure. Proceedings of the Institute of Mechanical Engineers Part C: Journal of Mechanical Engineering Sciences, Vol. 226, pp. 1210-1224, 2012. 
[49] Kitipornchai S, Xiang Y. Buckling of thick skew plates. International Journal for Numerical Methods in Engineering, Vol. 36, pp. 1299-1310, 1993.

[50] Xiang Y, Wang CM, Liew KM, Kitipornchai S. Mindlin plate buckling with prebuckling in-plane deformation. Journal of Engineering Mechanics, Vol. 119, pp. 1-18, 1993.

[51] Timoshenko SP, Gere JM. Theory of Elastic Stability. Second ed., New York: Dover Publication; 1961.

[52] Vrcelj Z, Bradford MA. A simple method for the inclusion of external and internal supports in the spline finite strip method (SFSM) of buckling analysis. Computers \& Structures, Vol. 86, pp. 529-544, 2008.

[53] Tham L, Szeto H. Buckling analysis of arbitrarily shaped plates by spline finite strip method. Computers \& Structures, Vol. 36, pp. 729-35, 1990.

[54] Shufrin I, Eisenberger M. Shear buckling of thin plates with constant in-plane stresses. International Journal of Structural Stability and Dynamics, Vol. 7, pp. 179-192, 2007.

[55] Elzein A, Syngellakis S. Dual reciprocity in boundary element formulations of the plate buckling problem. Engineering Analysis with Boundary Elements, Vol. 9, pp 175-84, 1992.

[56] Wang X, Yuan Z, Buckling analysis of isotropic skew plates under general in-plane loads by the modified differential quadrature method. Applied Mathematical Modelling, Vol. 56, pp. 83-95, 2018.

[57] Huyton P, York CB. Buckling of skew plates with continuity or rotational edge restraint. Journal of Aerospace Engineering, Vol. 14, pp. 92-101, 2001.

[58] Wang X, Tan M, Zhou Y. Buckling analyses of anisotropic plates and isotropic skew plates by the new version differential quadrature method. Thin-Walled Structures, Vol. 41, pp. 15-29, 2003.

[59] Xiang Y, Wang CM, Kitipornchai S, Liew KM. Buckling of triangular Mindlin plates under isotropic inplane compression. Acta Mechanica, Vol. 102, pp. 123-135, 1994.

[60] Xiang Y. Buckling of triangular plates with elastic edge constraints. Acta Mechanica, Vol. 156, pp. 63-77, 2002.

[61] Soares Jr RA, Palermo Jr L, Wrobel LC. Buckling of perforated plates using the dual reciprocity boundary element method. Boundary Elements and other Mesh Reduction Methods XLII, Vol. 126, pp. 89, 2019. 